\title{
Asymmetric Colour Matching: Memory matching vs. simultaneous
}

\section{matching}

M.D. de Fez ${ }^{*}$ P. Capilla, M.J. Luque, J. Pérez-Carpinell \& J.C. del Pozo

*Departamento I. de Optica, Escuela de Optica y Optometría, Universidad de

Alicante

Departamento de Optica, Facultad de Física, Universitat de València

\section{Abstract}

We have compared corresponding pairs obtained by simultaneous matching (haploscopic matching) and by memory matching (after 10 minutes) using 34 reference tests selected from the Munsell Atlas (glossy) belonging to the four main hues $5 Y, 5 G, 5 P B$ and $5 R P$. These colours lie very close to the $F_{1}$ and $F_{2}$ axis in the SVF space, where we have analysed our results. Illuminants $D_{65}$ and $A$ were used as reference and matching illuminants, respectively. Our results show, for both kinds of matching, a tendency to select more colourful colours than the original ones, with significant differences between matching and test colours, whereas hue does not seem to follow a definite pattern. This behaviour is similar to that found in colour matching experiments without illuminant changes. The analogy does not hold for lightness, which in the present experiment does not seem to follow a clear pattern. The best matching colours lie along the red-green axis and the worst matching colours along the blue-yellow axis.

KEY WORDS: colour memory, colour matching, memory matching, 
simultaneous matching, corresponding pairs, SVF space. 


\section{INTRODUCTION}

At present, it is becoming increasingly common to work with very different colour reproduction media (paper, slides, screens...) as well as with a great variety of environments, surrounds and lighting conditions. It is desirable to reproduce the appearance of coloured stimuli with the greatest possible accuracy. Modern colorimetry, by means of the appearance models (CIE $1976{ }^{1}$, Richter $^{2}$, Seim \& Valberg $^{3}$, Nayatani et al. ${ }^{4,5}$, Hunt ${ }^{6,7}$, Fairchild ${ }^{8,9,10}$, Fairchild \& Berns ${ }^{11}$, Nayatani ${ }^{12}$, Luo et al. ${ }^{13}$ ), aims to quantify colour perceptual descriptors under any observation or adaptation conditions, including illumination level, chromaticities of reference white and surround and the cognitive interpretation of the scene. The effect of adaptation conditions on colour appearance may be shown by matching experiments. Matching methods may be classified as simultaneous and successive according to the time elapsed between the presentation of the reference and the matching stimuli. We talk of simultaneous matching when the time interval between the two stimuli is zero. This method is often used in experiments on colour vision. When examining a pair of adjacent samples it is easy to judge whether they are equal or not, because the human visual system is very good at detecting small colour differences (see Kaiser \& Boynton ${ }^{14}$ for references). Nevertheless, discrimination thresholds differ from one observer to the next and depend on observation conditions. When the right conditions are met, humans can discriminate between very similar colours. From precise measurements of minimum perceptible differences in simultaneous matching, it can be affirmed that the human visual system may distinguish between above five million colours (Hunter et al. ${ }^{15}$ ).

Memory or successive matching occurs when there is any time delay 
between reference and matching stimuli. When the samples do not appear simultaneously, memory plays a role. In memory matching experiments, the physical sample is not present. Observers must match the colour they remember, under the same or different observation conditions. Therefore, they must resort to the image stored in their memory. This capability is employed in many of our daily activities.

When we study colour memory, the results may change depending on whether or not the stimulus colour is associated with a familiar object. Bartleson ${ }^{16}$ suggests that, due to the fact that most common objects in our environment are seen very often, we tend to have a stable image of them stored in our memory. It seems logical to think that the colours the observer associates with familiar objects will not be liable to the same time variations as the rest. The literature points out that, with familiar objects, remembered colours are significantly different from the original ones because colour memory tends to stress the chromatic attributes, and often results in saturation and lightness increments. Katz ${ }^{17}$, for instance, affirms that memory often exaggerates the more salient aspects of the colour of objects. In a recent paper (Pérez-Carpinell et al. ${ }^{18}$ ), we have shown that remembered colours are significantly different from the original ones, with changes in dominant wavelength and colorimetric purity.

Regarding surface colours, the experimental results show that variability is greater in successive than in simultaneous matching (Hamwi \& Landis ${ }^{19}$, Burnham \& Clark $^{20}$, Newhall et al. ${ }^{21}$, Nilsson \& Nelson ${ }^{22}$, Pérez-Carpinell et al. $\left.{ }^{23}\right)$. All the results suggest that the visual system cannot recall faithfully colour appearance after long intervals. Chromatic information stored in memory is considerably reduced by the visual system, and this fact results in gradual 
losses of colour discrimination with time.

The literature is not conclusive regarding how these discrimination losses between the viewing of the stimulus and its subsequent matching are produced. $\mathrm{Katz}^{17}$ found that remembered colours are exaggerated and that with large delay times the changes suffered by the remembered colour increase. From the work by Uchikawa \& $\mathrm{Ikeda}^{24,25}$ and Uchikawa ${ }^{26}$ it can be concluded that the colour discrimination capabilities of the visual system is impaired in successive matching in the same amount for any of the perceptual attributes. In our work on surface colours (Pérez-Carpinell et al. ${ }^{23}$ ) we have found a tendency towards lower discrimination with increasing time, at least for 15 second, 15 minutes and 24 hour delays, due to increases of remembered chroma and to changes in remembered lightness that depend on the original lightness. Conversely, Hanawalt \& Post $^{27}$ did not find any effect of time on colour descriptors, and Hamwi \& Landis ${ }^{19}$ obtained the same dispersion in their measurements after 15 minutes, 24 hours and 65 hours. Although decrements in lightness and saturation occur, they could not reach a conclusion regarding hue.

The observer's skill to judge colour differences between pairs of stimuli in any matching experiment must be measured by a parameter describing adequately the perceptual colour difference between stimuli. Therefore, the choice of the representation space is of the greatest importance. Non-euclidean spaces with point dependent metrics are awkward to use. The euclidean metric is desirable for simplicity of computation and ease in the interpretation of the results, but it requires spaces as uniform as possible. During the past years several colour representation spaces and colour models with different uniformity degrees have been defined, including several revisions of the CIELAB space. 
Some of these spaces and models aim mainly to reproduce the different neural stages of the visual process, whereas others just aim to define colour descriptors and to establish a colour difference formula. Among this last group, we carried out a comparative analysis of our colour memory experiments with surface colours (de Fez et al. $^{28}$ ), using five representation spaces, CIELAB, CIELUV, LLAB, RLAB and SVF. In that study, we concluded that SVF space ${ }^{3,29}$ (see Apendix) is the most adequate for this kind of analysis, since it the constant Munsell Chroma and Munsell Hue loci and besides it reproduces the response of different cell types along the visual pathway.

In previous works (Pérez-Carpinell et al. $^{23}$, de Fez et al. ${ }^{28}$ ) we have compared simultaneous vs. memory matching under $D_{65}$. The aim of this work is to perform a series of experiments to understand the effect of memory on the appearance of the remembered colour when the original and matching samples are seen under different illuminants. To this end, we compare asymmetric simultaneous matching with asymmetric memory matching, using the SVF representation space to study the variations of the perceptual descriptors and the total colour difference $\Delta \mathrm{E}$ between matching and original colours.

\section{EXPERIMENTAL SET-UP}

The experimental set-up consisted of a modified matching Macbeth cabinet, with simulated $D_{65}$ and $A$ illuminants. The left half of the cabinet was seen under $D_{65}$, and the right half under illuminant $A$. Both halves were separated by a grey panel of the same chromaticity and luminance factor as the walls of the cabinet (see Figure 1-a). 
The change of illuminant between the reference and the matching conditions led us to inquire whether the SVF space would keep the same properties that made it convenient for our previous work. SVF space is more uniform than most colour spaces (Seim \& Valberg ${ }^{3}$, Valberg et al. ${ }^{29}$, Mahy et al. ${ }^{30}$ ). Moreover, the SVF formula describes well the colour differences in a number of experiments, including the prediction of colour differences under illuminant changes (Seim \& Valberg ${ }^{3}$ ). In addition we have chedked that, in this space, the colour differences between Breneman's corresponding pairs $\left(\right.$ Breneman ${ }^{31}$ ) are small (see Table I for an example). As this space predicts near zero colour differences between stimuli perceived equal under different illuminants, we admit that colour appearance is adequately predicted under illuminant changes $\left(\mathrm{de} \mathrm{Fez}^{32}\right)$.

\section{Table I}

The samples used as reference and comparison tests were $17 \times 20-\mathrm{mm}$ glossy Munsell chips, from the 1976 Munsell Atlas edition. As reference tests we selected the four main hues $5 Y, 5 G, 5 P B, 5 R P$, and for each Hue, we took three Munsell Chromas $(\mathrm{C}=4,6,8)$ and three different Munsell Values for each Chroma $(V=3,5,7)$, except for $Y$, because the Atlas does not include samples with $\mathrm{C}=6$ and 8 at $\mathrm{V}=3$. The comparison samples belonged to the four Munsell charts of the same Hue as the reference test, that is, 2.5T, 5T, 7.5T and 10T, where T stands for each of the Hues used in this study.

Figure 1-b plots the 34 reference tests on a $F_{1}-F_{2}$ plane in SVF space. The four main Hues selected were those closest to the $F_{1}$ and $F_{2}$ axis of SVF space $^{30}$. Plotting the Munsell samples on constant $\mathrm{V}$ planes we ascertained which samples had neighbouring samples with $\mathrm{V}$ and $\mathrm{C}$ values above and 
below those of the reference sample, on its chart as well as on the previous and following charts. This ensures that the observers will have enough liberty of choice in the two experiments of the present study.

The reference sample was always seen under $D_{65}$ in the left half of the cabinet, against a white background of chromaticity coordinates $x=0.338, y=$ 0.358 and luminance $389 \mathrm{~cd} / \mathrm{m}^{2}$, equal to the background of the Munsell charts. In the right half of the cabinet, the observer viewed the four Munsell charts corresponding to the same main Hue than the reference test. In this case, the chromaticity coordinates of the background are different due to the illuminant change: $x=0.472, y=0.418$ and luminance $473 \mathrm{~cd} / \mathrm{m}^{2}$. The $\mathrm{CIE}$ illumination and observation geometry was $0^{\circ} / 45^{\circ}$, at an observation distance of $40 \mathrm{~cm}$.

Ten observers, four women and six men, took part in the experiment. The observers' mean age was 30 , and all were classified as normal by the Ishihara test. All the observers underwent a control simultaneous symmetric matching experiment with four Munsell chips, of different hues, under illuminant A. For all observers, test and match samples were physically identical.

\section{Memory matching}

Our study began with the memory matching experiment; in this way, the simultaneous matching experiment would not influence memory. To keep viewing conditions in both experiments as similar as possible, and since the simultaneous matching experiment would be carried out haploscopically, observers viewed monocularly the reference and comparison test in the memory matching experiment. Observers adapted their left eye to the memorisation illuminant $D_{65}$ for three minutes. During this time, the right half of 
the cabinet was kept dark. Then, they had 10 seconds to memorise the first reference test, seen on a white background. After 10 minutes the observer started the recognition task. The first seven minutes, the observer was darkadapted and during the last three minutes, was adapted to illuminant $A$. The observer was then shown the four Munsell charts of the corresponding hue, in a random order. The observer's task was to select, among all the comparison Munsell chips, the sample most similar to the colour stored in their memory. If the observers did not find a match or if they hesitated to chose between several samples, they were allowed to inspect additional Munsell charts. This procedure was repeated for each of the reference test of a given session.

Sessions took always less than 90 minutes, and no time limit was set for the recognition task. In each session, frequent pauses were made to avoid fatiguing the observer.

\section{Simultaneous matching}

Observers matched samples haploscopically, so as to be able to view simultaneously the test and matching samples under different adaptation conditions. In this experiment, observers adapted both eyes simultaneously for three minutes, the left eye to illuminant $D_{65}$ and the right eye to illuminant $A$. After this adaptation interval, the reference test was viewed under $D_{65}$, and the four comparison charts under A, as in the memory matching experiment. The observer's task was to select the Munsell sample that matched the reference test. Again, observers were allowed to view additional charts when necessary. This happened frequently in this experiment, due to the change in perceptual attributes caused by the illuminant change. 
This procedure was repeated for the 34 reference samples, In each measurement session, taking about 30 minutes in average, the observer was shown the nine samples corresponding to one of the main hues.

In this experiment, the observer was required to rate the goodness of the match in a scale from one to four $(\mathrm{Q}: 1=$ bad, $2=$ =indifferent, 3=good, 4=very good). The value "1" meant that the observer was unable to find a match, and in this case the measurement was repeated in other session. Note that this goodness parameter cannot be used in the memory matching experiment.

\section{RESULTS}

Figures 2a-i show the mean results of the matching experiments for all subjects on the $F_{1}-F_{2}$ plane for each of the nine combinations of $V$ and $C$ values.

\section{Figures 2}

We computed the lightness magnitude $\Delta \mathrm{V}_{\mathrm{y}}$, chroma $\Delta \mathrm{C}$, hue $\Delta \mathrm{h}$ increments and the total colour difference $\Delta \mathrm{E}$ between the reference test and the matching samples, in order to analyse the behaviour of the different colour descriptors. Table II shows these increments, computed with the memory matching data. The results for the simultaneous matching experiment appear in Table III. In Table IV, we compute the differences between the mean matching colours obtained in simultaneous and memory matching.

Tables II, III, IV

Figure 3 shows the colour differences $\Delta \mathrm{E}$ resulting from comparing the reference test with the memory matching sample, the reference test with the simultaneous matching sample and the matching samples of both experiments. 
Figure 3

The analysis of the behaviour of the lightness magnitude, the chroma and the value of the samples have been carried out from the data in Figure 3 and Tables II-IV.

\section{Analysis of the lightness magnitude}

Remembered lightness does not follow a fixed pattern: RP and $\mathrm{Y}$ are remembered as lighter than the original colour. This happens also to $\mathrm{G}$, except for $5 / 4$ and 5/8, whereas $P B$ is remembered as darker, $3 / 8,7 / 4$ and $7 / 6$ excepted.

In the simultaneous matching experiment, PB tends to be matched by samples with $V_{y}$ values lower than the original ones, $G$ and $Y$ with samples with greater $\mathrm{V}_{\mathrm{y}}$ and $\mathrm{RP}$ does not exhibit a definite behaviour. The smaller $\Delta \mathrm{V}_{\mathrm{y}}$ values are below one in most cases.

The matching samples in the memory matching experiment are generally lighter than those chosen in simultaneous matching for RP and $\mathrm{Y}$, but darker for $P B$ and $G$.

\section{Analysis of chroma}

With the pair of illuminants used, remembered colours are always more chromatic than the original ones. This happens also in the simultaneous matching experiment, except for $5 \mathrm{G} 7 / 8$, that is matched by a sample with slightly smaller chroma.

Chroma increments by memory are, in general, greater than in simultaneous matching, except for $P B 7 / 8, G 5 / 8$ and $Y 7 / 8$, for which the 
increments are smaller, and for PB $3 / 8$ and $7 / 4$, for which the increments are equal.

\section{Analysis of hue}

By memory, all the hue angles increase, that is, $P B, G, R P$ and $Y$ are remembered as more purplish, more green-bluish, more reddish and more yellow-greenish, respectively.

In simultaneous matching, PB and $\mathrm{Y}$ tend towards larger hue angles, so that the stimuli look more purplish and yellow-greenish, respectively, whereas $G$ tends towards smaller hue angles and the appearance of the samples is therefore more yellow-greenish, unlike what happened in memory matching. RP does not follow a clear trend, because the matching samples can be indifferently more reddish or more purplish, always with small $\Delta \mathrm{H}$ variations.

\section{Analysis of the total colour difference}

The best and worst matching colours are shown in Table V. The largest colour differences between remembered and original colour appear in $\mathrm{Y}$ samples with large $V_{y}$ values and for PB samples with small $V_{y}$ values. In simultaneous matching, PB and $\mathrm{Y}$ show the largest colour differences between matching and original colours, with equal colour differences for the worst matched colours, $\mathrm{Y} 7 / 6$ and $7 / 8,(\Delta E=6.97)$, although $\mathrm{Y} 7 / 6$ shows a larger standard deviation. The simultaneous matches were always described at least as good (Q>2.5), except for PB 7/8. 
All the colour differences between matching and original colours are smaller than the differences between remembered and original colours, excepting PB 7/6, for which the colour difference is slightly larger in simultaneous matching, and $Y 3 / 4$ and $G 5 / 8$, that show the same colour differences in both experiments. The total colour differences are due largely to the contribution of Chroma. Both the simultaneous matching and the memory matching colours are more chromatic than the original, although the remembered colour is always the most chromatic of the three.

The chips presenting the largest differences between average memory matching and simultaneous matching colours are RP $5 / 4(\Delta \mathrm{E}=6.45)$ and $\mathrm{Y} 5 / 8$ (5.92). Colour differences are smallest for PB 7/4 ( $\Delta \mathrm{E}=0.72), 7 / 8(0.76)$ and $Y$ $3 / 4(0.81)$. In general, standard deviations are larger in the memory matching experiment.

\section{Statistical analysis of the colour differences}

There is a tendency to treat experimental results by means of an analysis of variance (ANOVA) or even with the t-test. In both cases, it is assumed that the experimental data follow a normal distribution, though this is not always the case, as in our experiments.

For this reason, we decided to use a non-parametric test that did not require the normality condition. Among the different non-parametric tests at our disposal, we choose the Mann-Whitney or Wilconson test, which is considered as the non-parametric alternative to the t-test for two samples, which would be the parametric test more suitable for our data $\left(\right.$ Conover $\left.^{33}\right)$.

The choice of this test presents two main advantages. The first one, that 
the test is valid regardless of the random variable under study, that is, the distribution of the random variable does not need to be normal for the test to be applied. The second one is that this test is more reliable than most non parametric tests ${ }^{33}$.

We are going to discuss those cases in which the analysis does allow us to reject the hypothesis that the colour difference between two samples is zero $(\alpha=0.05)$. In Table VI we show the pairs of colour differences between memory matching and original colours in which we find statistically significant differences. Their correspondent significance value is also shown.

Table VI

In some cases, statistically significant differences in $\Delta \mathrm{V}_{\mathrm{y}}, \Delta \mathrm{C} \circ \Delta \mathrm{h}$ do not result in statistically significant differences in $\Delta \mathrm{E}$ for both experiments. In other cases, we find statistically significant differences in $\Delta \mathrm{E}$, but not in any of the three perceptual attributes. In our analysis, we have chosen to point out only those cases for which the colour differences are significant, giving more weight to the global colour appearance than to the individual perceptual parameters.

\section{DISCUSSION}

Our results show that remembered lightness behaves differently depending on whether memorisation and matching illuminants are the same or not. This can be seen if we compare the present results with those obtained in a memory matching experiment with surface colours (Pérez-Carpinell et $a l{ }^{23}$ ), where both memorisation and matching were made under $D_{65}$. In that paper, remembered lightness was shown to be dependent on the lightness of the reference sample. In the present work, we have found that with a change of 
illuminant between the memorisation and matching stages, this result is not reproduced. In fact, we cannot conclude anything about the behaviour of lightness, because the different samples do not follow a common trend. Regarding chroma, nevertheless, the matching samples both in simultaneous and memory matching are more colourful than the original ones for the two illuminants used ${ }^{23}$.

Under our experimental conditions, the best remembered colours are $G$ $7 / 8$ and $3 / 8$ and the worst remembered colours are $Y 7 / 6$ and 5/8. On the other hand, the best simultaneously matched colours are $G 3 / 8,5 / 6$ and $7 / 6$ y RP 5/4 and the worst $Y 7 / 6$ and $7 / 8$ and PB 5/8. Figure 1-b shows that these samples lie close to the $F_{1}=0$ and $F_{2}=0$ axis and besides the lie also close to the redgreen and blue-yellow axis of Boynton's space ${ }^{34}$. So, the best remembered colours in memory matching lie along the red-green direction, whereas the worst remembered are along the yellow-blue direction. This is also true of simultaneous matching experiment, regardless of the fact that the reference and matching illuminants be the same or not (Pérez-Carpinell et al. ${ }^{23}$ ). It is tempting to hypothesise that one of the visual channels performs better in memory tasks than the other. Although this hypothesis would follow the line of known results in the literature, which demonstrate that discrimination thresholds from a given stimulus are smaller along the red-green than along the blue-yellow direction, it would be premature to state a final conclusion.

The perceptual parameters of the matching and the test colours ought to be the same. If both stimuli are also physically the same, we would have perfect colour constancy, and if not, we would have a given degree of constancy or even no constancy at all. In a chromaticity diagram that is not associated to the 
perceptual space, such as $(x, y)$ or $\left(u^{\prime}, v^{\prime}\right)$, the chromaticity coordinates of the corresponding pair are different. Nevertheless, our results show that the perceptual parameters of the best matching sample and the reference test are different. This might be due to the following reasons:

a) The SVF space does not describe well enough the appearance of colours. But, as can be shown by predicting the Brenneman's corresponding pairs (de Fez ${ }^{32}$ ), the differences between the SVF coordinates of each pair are very small (close to $10^{-2}$ ). This problem must be therefore, a minor one.

b) The Munsell Atlas is discrete and this influences the results. The observers are not at liberty to chose colours with any chromaticity coordinates, but only those in the Atlas. In this way, it is probable that the sample whose perceptual parameters match perfectly the reference sample will be not in the Atlas. To minimise this effect, it would be necessary to have a uniform sampling of Munsell chips around the corresponding pair, in such a way that the mean of a large number of matches would be as close as possible to that sample. Nevertheless, the Munsell Atlas is less uniform under illuminant $A$ than under illuminant $D_{65}\left(\right.$ Fairchild $\left.^{10}\right)$. In Figure 4, we plot contours of constant Munsell Chroma and Value under illuminant $D_{65}$ and $A$. It can be seen that the contours are more circular under $D_{65}$. We have assumed that this is due solely to the loss of uniformity of the Munsell Atlas, and not to inadequacies of the SVF space.

Figure 4

If memory were perfect, corresponding pairs in memory matching would have the same appearance, and consequently, the same perceptual descriptors. In general, remembered and original colours are significantly different. We have found that the memory matching colour is in most cases (31 
among our 34 reference tests) more separated from the reference colour than the simultaneous matching colour. These results apparently contradict Uchikawa et al. ${ }^{35}$, although it must be noted that their data are analysed in CIELUV, space that we did not use in our work because of its lack of uniformity and for the poor performance of its chromatic adaptation transform, unable to predict adequately corresponding pairs for illuminants $D_{65}$ and $A$, for instance.

If memory matching colours were nearer the original test than simultaneous matching colours, this might be taken as evidence that the observer had minimised somehow the effect due to the change of illuminant, reducing the uniformity problem. But it might also be due to a partial discount of the illuminant in the traditional sense, that is, the memory colour would be more physically similar to the original colour. It would be impossible to separate both effects. Our results show that memory colours are not, in general, nearer to the reference colours than the simultaneous matching colours. We may conclude, at least, that memory does not contribute to minimise the effect of the illuminant on uniformity.

Nevertheless, we cannot affirm that memory does not contribute to constancy, because we cannot separate the contributions of memory and uniformity just from the results of a single experiment. Besides, it is not possible to know either to what degree the discount of illuminant is due only to memory. Even using a uniform sampling under illuminant $A$, we would still be unable to ascertain whether memory has contributed or not to colour constancy. It would be necessary to compare the colour shifts measured under our experimental conditions with results obtained with other spatial configurations, such as isolated colours, that do not show colour constancy, or Mondrians, that yield a 
greater degree of constancy than test-background configurations, as has been studied both in simultaneous matching (Arend \& Reeves ${ }^{36}$, Brainard \& Wandell ${ }^{37}$ ) and in memory matching (Jin \& Shevell ${ }^{38}$ ). 


\section{APENDIX}

In what follows, we resume briefly the equations of SVF. The interested reader should refer to the original work by Seim and Valberg ${ }^{3}$ ('Towards a uniform color space: a better formula to describe the Munsell and OSA color scales'. Color Res. Appl. 11, 11-24, 1986).

Let us consider a stimulus defined by chromatic coordinates $(x, y)$ and luminance factor $\mathrm{Y}$ under illuminant $\mathrm{C}$. We compute the corresponding tristimulus values, with $Y$ normalised to 1 , and from this we obtain the relative cone excitations, $S_{i}^{\prime}$, by means of the following transform:

$$
\left(\begin{array}{l}
S_{1}^{\prime} \\
S_{2}^{\prime} \\
S_{3}^{\prime}
\end{array}\right)=\left(a_{i j}\right)\left(\begin{array}{l}
X \\
Y \\
Z
\end{array}\right)
$$

Matrix $\left(a_{i j}\right)$ is chosen to obtain Pitt's fundamentals (1944), although Seim and Valberg ascertained that the results do not change significantly if Walraven's (1974) or Smith and Pokorny's (1975) or Estévez's (1979) fundamentals are used. Taking into account that the normalised tristimulus values of illuminant $\mathrm{C}$ are $X_{w}=0.9817, Y_{w}=1, Z_{w}=1.1818$, the relative cone excitations of the illuminant are computed as follows:

$$
\left(\begin{array}{l}
S_{1 W}^{\prime} \\
S_{2 W}^{\prime} \\
S_{3 W}^{\prime}
\end{array}\right)=\left(a_{i j}\right)\left(\begin{array}{l}
X_{w} \\
Y_{W} \\
Z_{W}
\end{array}\right)
$$

The model includes a von Kries-type chromatic adaptation stage. The 
relative cone excitations $S^{\prime}{ }_{i w}$ determine the coefficients of the adaptation matrix:

$$
\left(\begin{array}{l}
S_{1} \\
S_{2} \\
S_{2}
\end{array}\right)=\left(\begin{array}{ccc}
1 / S_{1 W}^{\prime} & 0 & 0 \\
0 & 1 / S_{2 W}^{\prime} & 0 \\
0 & 0 & 1 / S_{2 W}^{\prime}
\end{array}\right)\left(\begin{array}{l}
S_{1}^{\prime} \\
S_{2}^{\prime} \\
S_{3}^{\prime}
\end{array}\right)
$$

The equations to derive the responses of the three types of cone, $v(S)$, have the following general form:

$$
v(S)=\left\{\begin{array}{c}
\frac{\left(S-S_{0}\right)^{n}}{\left(S-S_{0}\right)^{n}+k} \text { si } \quad S \geq S_{0} \\
0 \text { si } \quad S<S_{0}
\end{array}\right.
$$

where $S_{0}$ is a threshold value. The final response of each cone mechanism is computed as follows:

$$
\mathrm{V}(\mathrm{S})=\mathrm{V}_{\mathrm{M}} \mathrm{V}(\mathrm{S})
$$

where the scaling constant $V_{M}$ is different for each mechanism. In particular, the cone responses to an achromatic stimulus is obtained from the following equation:

$$
V_{1}(Y)=\left\{\begin{array}{c}
\frac{(100 Y-0.43)^{0.51}}{(100 Y-0.43)^{0.51}+31.75} \text { si } Y \geq 0.0043 \\
0 \text { si } Y<0.0043
\end{array}\right.
$$


and

$$
\mathrm{V}_{\mathrm{Y}}=40 \mathrm{v}_{1}(\mathrm{Y})
$$

$V_{Y}$ and two opponent coordinates, $F_{1}$ and $F_{2}$, computed from the cone responses, are the stimulus descriptors. The opponent coordinates are a transform of the values $p_{1}$ and $p_{2}$, defined as follows:

$$
\begin{aligned}
& \mathrm{p}_{1}=\mathrm{v}_{1}\left(\mathrm{~S}_{1}\right)-\mathrm{v}_{1}(\mathrm{Y}) \\
& \mathrm{p}_{2}=\left\{\begin{array}{lll}
\mathrm{v}_{1}\left(\mathrm{~S}_{3}=Y\right)-\mathrm{v}_{1}\left(\mathrm{~S}_{3}\right) & \text { si } & \mathrm{S}_{3} \leq \mathrm{Y} \\
\mathrm{v}_{2}\left(\mathrm{~S}_{3}=Y\right)-\mathrm{v}_{2}\left(\mathrm{~S}_{3}\right) & \text { si } & S_{3}>Y
\end{array}\right.
\end{aligned}
$$

where values $v_{1}\left(S_{3}\right)$ and $v_{1}\left(S_{1}\right)$ are computed by respectively substituting $S_{3}$ and for $S_{1}$ for $Y$ in $(A .6), v_{2}(Y)$ is computed as

$$
v_{2}(Y)=\left\{\begin{array}{c}
\frac{\left(100 \mathrm{Y} / \mathrm{k}\left(\mathrm{V}_{\mathrm{Y}}\right)-0.1\right)^{0.86}}{\left(100 \mathrm{Y} / \mathrm{k}\left(\mathrm{V}_{\mathrm{Y}}\right)-0.1\right)^{0.86}+103.2} \text { si } \mathrm{Y} \geq 0.001 \mathrm{k}\left(\mathrm{V}_{\mathrm{Y}}\right) \\
0 \text { si } \mathrm{Y}<0.001 \mathrm{k}\left(\mathrm{V}_{\mathrm{Y}}\right)
\end{array}\right.
$$

where:

$$
\mathrm{k}\left(\mathrm{V}_{\mathrm{Y}}\right)=0.140+0.175 \mathrm{~V}_{\mathrm{Y}}
$$

and $v_{2}\left(S_{3}\right)$ is obtained by substituting $S_{3}$ for $Y$ in (A.10). Finally, the opponent coordinates $F_{1}, y F_{2}$, are computed as follows:

$$
\begin{aligned}
& F_{1}=700 p_{1}-54 p_{2} \\
& F_{2}=96.5 p_{2} \quad(A .13)
\end{aligned}
$$


The colour difference between two stimuli is obtained from the differences between the descriptors $V_{Y}, F_{1}$ and $F_{2}$ of each colour, although the lightness magnitude $V_{Y}$ is weighted by a factor 2.3 , as can be seen in the following equation:

$$
\Delta \mathrm{E}=\sqrt{\left(\Delta \mathrm{F}_{1}\right)^{2}+\left(\Delta \mathrm{F}_{2}\right)^{2}+\left(2.3 \Delta \mathrm{V}_{\mathrm{Y}}\right)^{2}}(\mathrm{~A} .14)
$$




\section{Bibliography}

1. Publication CIE 15.2-1986 Colorimetry, $2^{\text {nd }}$ Edition (1986).

2. M. Richter. Cube-root color spaces and chromatic adaptation. Color Res. Appl. 5, 25-43 (1980).

3. T. Seim, \& A. Valberg, Towards a uniform color space: a better formula to describe the Munsell and OSA color scales. Color Res. Appl. 11, 11-24 (1986).

4. Y. Nayatani, K. Hashimoto, K. Takahama \& H. Sobagaki, A nonlinear colorappearance model using Estévez-Hunt-pointer primaries. Col.Res. Appl. 12, 231-242 (1987).

5. Y. Nayatani, K. Takahama, H. Sobagaki \& K. Hashimoto, Color-appearance model and chromatic-adaptation transform. Color Res. Appl. 15, 210-221 (1990).

6. R.W.G.Hunt, Revised colour-appearance model for related and unrelated colours. Col. Res. Appl., 16, 146-165 (1991).

7. R.W.G.Hunt, An improved predictor of colourfulness in a model of colour vision. Color Res. Appl. 19, 23-33 (1994).

8. M.D. Fairchild, Formulation and testing of an incomplete-chromaticadaptation model. Color Res. Appl. 15, 243-250 (1991).

9. M.D. Fairchild, Refinement of the RLAB color space. Color Res. Appl. 21, 338-346 (1996).

10. M.D. Fairchild, Color Appearance Models, Addison-Wesley (1998).

11. M.D. Fairchild \& R.S. Berns, Image color-appearance specification through extension of CIELAB. Color Res. Appl. 18, 178-190 (1993). 
12. Y. Nayatani, Revision of chroma and hue scales of a nonlinear colorappearance model. Color Res. Appl. 20, 143-155 (1995).

13. M.R. Luo, M.C. Lo \& W.G. Kuo, The LLAB(I:C) colour model. Color Res. Appl. 21, 412-429 (1996).

14. Kaiser P K and Boynton R M. Human Color Vision. Optical Society of America, Washington D. C., (1996)

15. R.S. Hunter \& R.W. Harold, The measurement of appearance, pag 54, John Wiley \& Sons, New York, USA (1987)

16. C.J. Bartleson, Memory colors of familiar objects. J. Opt. Soc. Am. 50, 7377 (1960).

17. D. Katz, The world of colour. Trubner \& Co. London (1935)

18. J. Pérez-Carpinell, M.D. de Fez, R. Baldoví \& J.C. Soriano, Familiar objects and memory color. Color Res. Appl. 23, 416-427 (1998b).

19. V. Hamwi \& C. Landis, Memory for color. J. Psychol. 39, 183-194 (1955).

20. R.W. Burnham \& J.R. Clark, A test of hue memory. J. Appl. Psychol. 39, 164-172 (1955).

21. S.M. Newhall, R.W. Burnham \& J.R. Clark, Comparison of successive with simultaneous color matching. J. Opt. Soc. Am. 47, 43-56 (1957).

22. T.H. Nilsson \& T.M. Nelson, Delayed monochromatic hue matches indicate characteristics of visual memory. J. Exp. Psychol. Human Percept. Perform. 7, $141-150$ (1981).

23. J. Pérez-Carpinell, R. Baldoví, M.D. de Fez \& J. Castro, Color memory matching: time effect and other factors. Color Res. Appl. 23, 234-247 (1998). 
24. K. Uchikawa \& M. Ikeda, Temporal deterioration of wavelength discrimination with successive comparison method. Vision Res. 21, 591-595 (1981).

25. K. Uchikawa K. \& M. Ikeda, Accuracy of memory for brightness of colored lights measured with successive comparison method. J. Opt. Soc. Am. A, 3, 3439 (1986).

26. K. Uchikawa, Purity discrimination: successive vs simultaneous comparison method. Vision Res. 23, 53-58 (1983).

27. N.G. Hanawalt \& B.E. Post, Memory trace for color. J. Exp. Psychol. 30, 216-227 (1942).

28. M.D. de Fez, M.J. Luque, P. Capilla, J. Pérez-Carpinell, M.A. Díez, Colour memory matching analysed using different representation spaces. J.Opt. 29, 287-297 (1998).

29. A. Valberg, T. Seim, B.B. Lee \& J. Tryti, Reconstruction of equidistant color spaces from reponses of visual neurones of macaque. J. Opt. Soc. Am A 3, 1726-1734 (1986).

30. M. Mahy, L. Van Eycken \& A. Oosterlink, Evaluation of uniform color spaces developed after the adoption of CIELAB and CIELUV. Color Res. Appl., 19, 105-121 (1994).

31. E.J. Breneman, Corresponding chromaticities for different states of adaptation to complex visual fields. J. Opt. Soc. Am. A, 4, 1115-1129 (1987).

32. M.D. de Fez, Estudio de diversos factores que afectan a la memoria del color. Ph. D. Thesis. Universidad de Valencia (1999). 
33. W.J. Conover, Practical nonparametric statistics. John Wiley \& Sons. New York, USA (1971).

34. R.M. Boynton, A system of photometry and colorimetry based on cone excitations, Color Res. And Appl., 11, 244-252 (1986).

35. K. Uchikawa, Y. Kuriki \& Y. Tone, Measurement of color constancy by color memory matching, Optical Review, 5, 59-63 (1998)

36. L. Arend \& A. Reeves, Simultaneous color constancy, J. Opt. Soc. Am A, 3, 1743-1751 (1986).

37. D.H. Brainard \& B. Wandell, Asymmetric color matching:how color appearance depends on the illuminant, J. Opt. Soc. Am A, 9, 1433-1448 (1992).

38. E.W. Jin \& S.K. Shevell, Color memory and color constancy, J. Opt. Soc. Am., 13 1981-1991 (1996). 


\section{Figure Legends}

Figure 1: Experimental set-up: a) Matching Macbeth cabinet with simulated $D_{65}$ an A illuminants, b) Reference tests in the SVF space.

Figure 2: Reference tests $(X)$, mean $( \pm s d)$ memory matching colour $(O)$ and mean $( \pm s d)$ simultaneous matching colour $(\bullet)$ plotted in the $F_{1}-F_{2}$ plane

Figure 3: Representation of the colour difference $\Delta \mathrm{E}$ for each combination of Munsell Value and Chroma, a) $\Delta \mathrm{E}$ between reference tests and memory matching colour; b) $\Delta \mathrm{E}$ between reference tests and simultaneous matching colour; c) $\Delta \mathrm{E}$ between simultaneous matching and memory matching colours.

Figure 4: Contours of constant Munsell Hue and Chroma (Value=5) plotted in the $F_{1} F_{2}$ plane, a) under illuminant $D_{65}$, b) under illuminant $A$. 
Figure 1-a

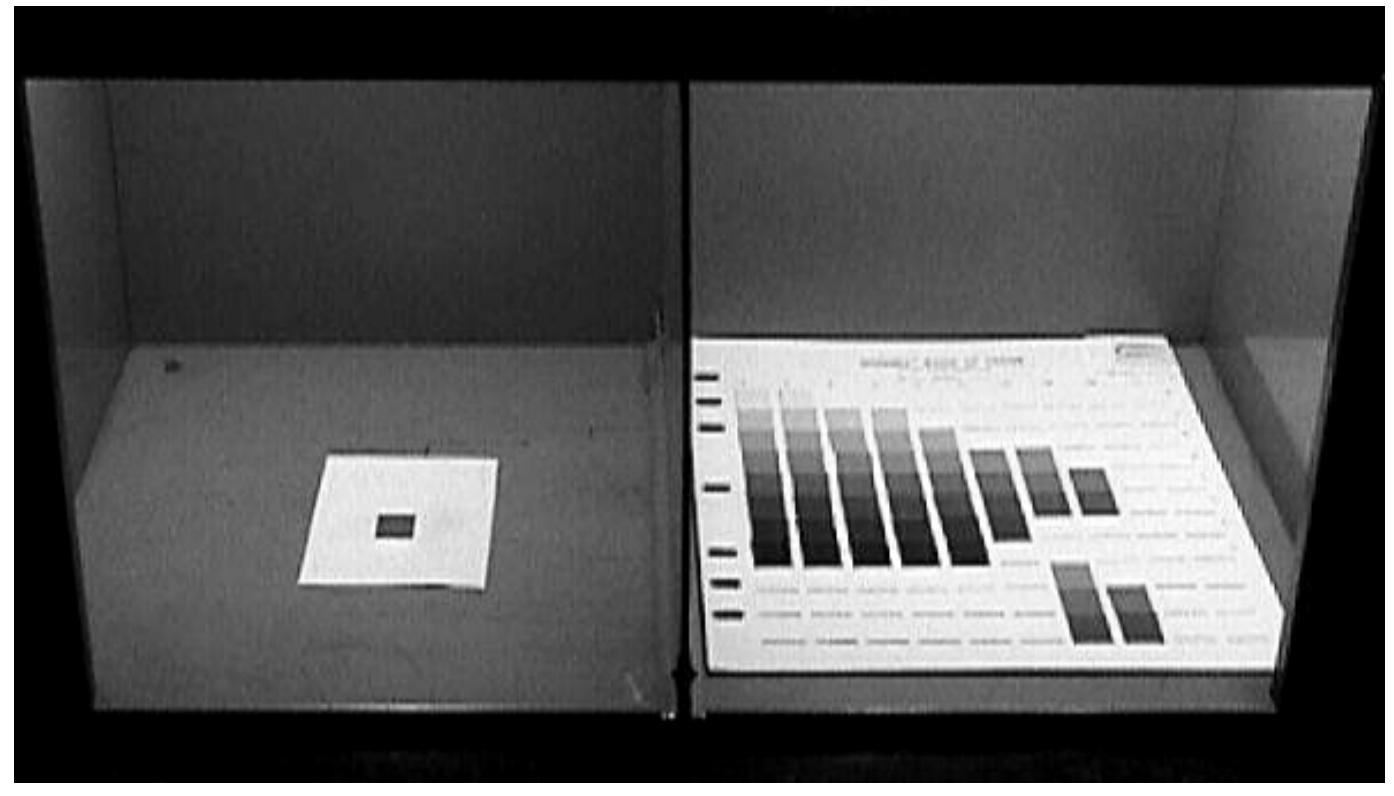


Figure 1-b

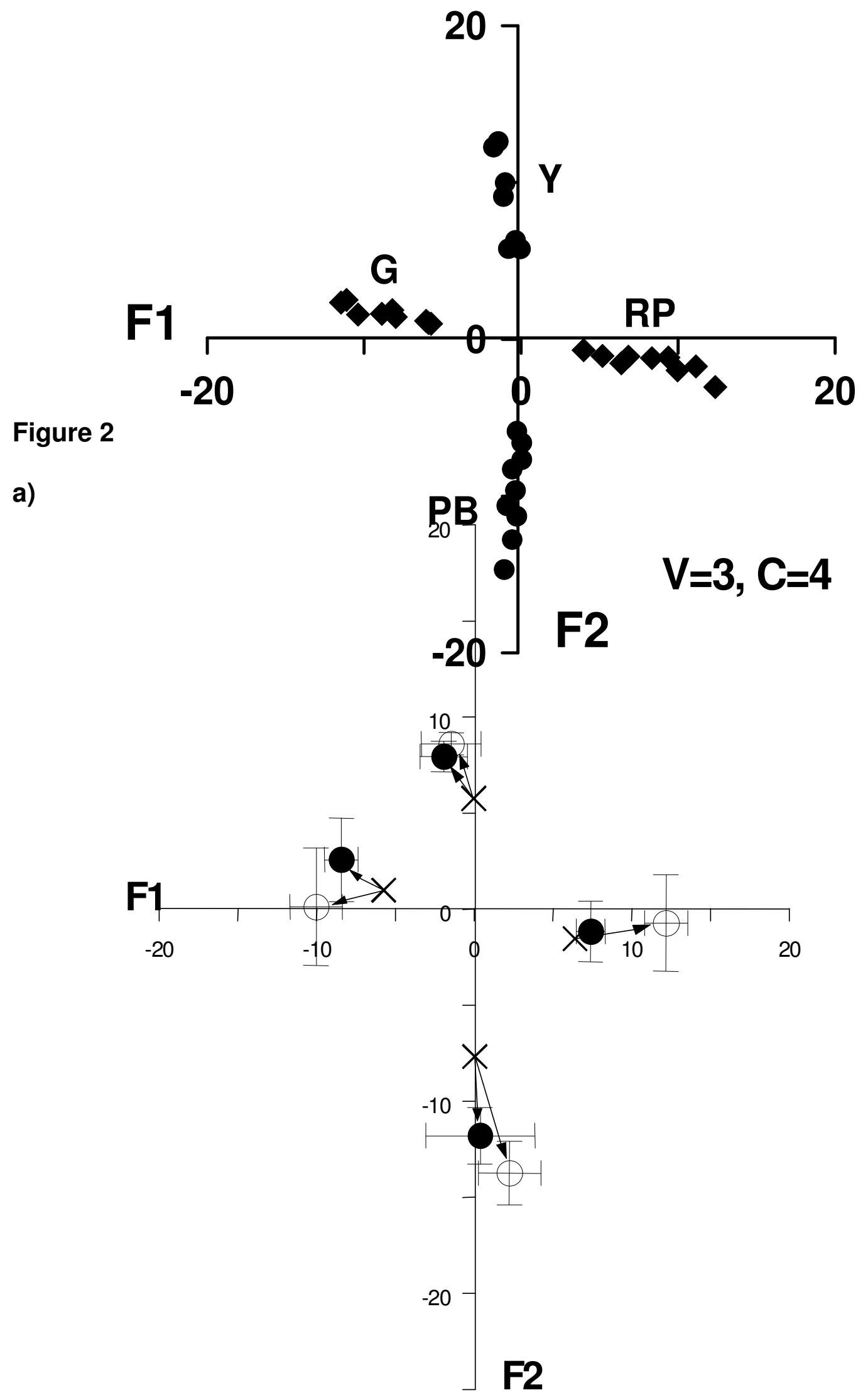


Figure 2

b)

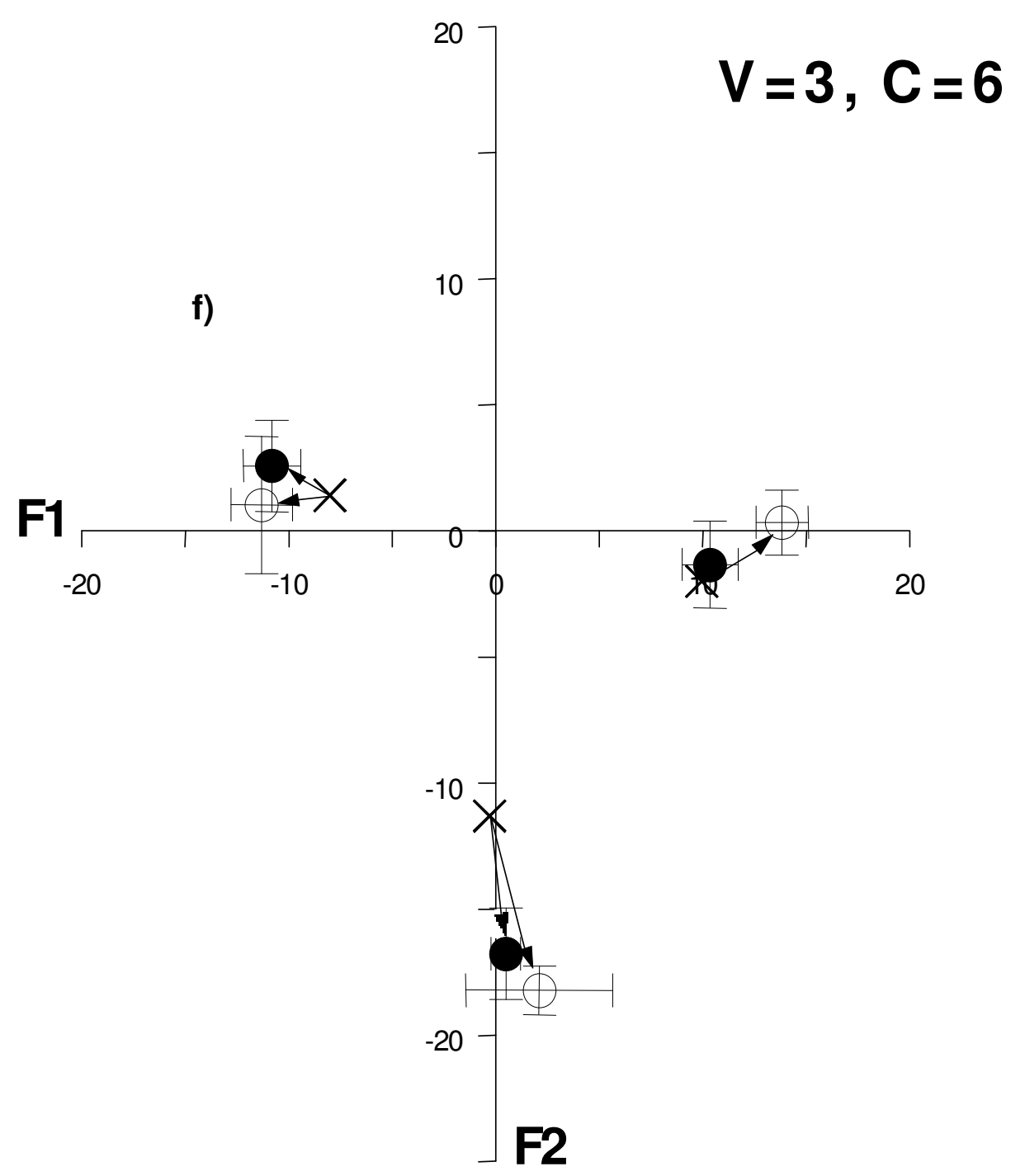


Figure 2

c)

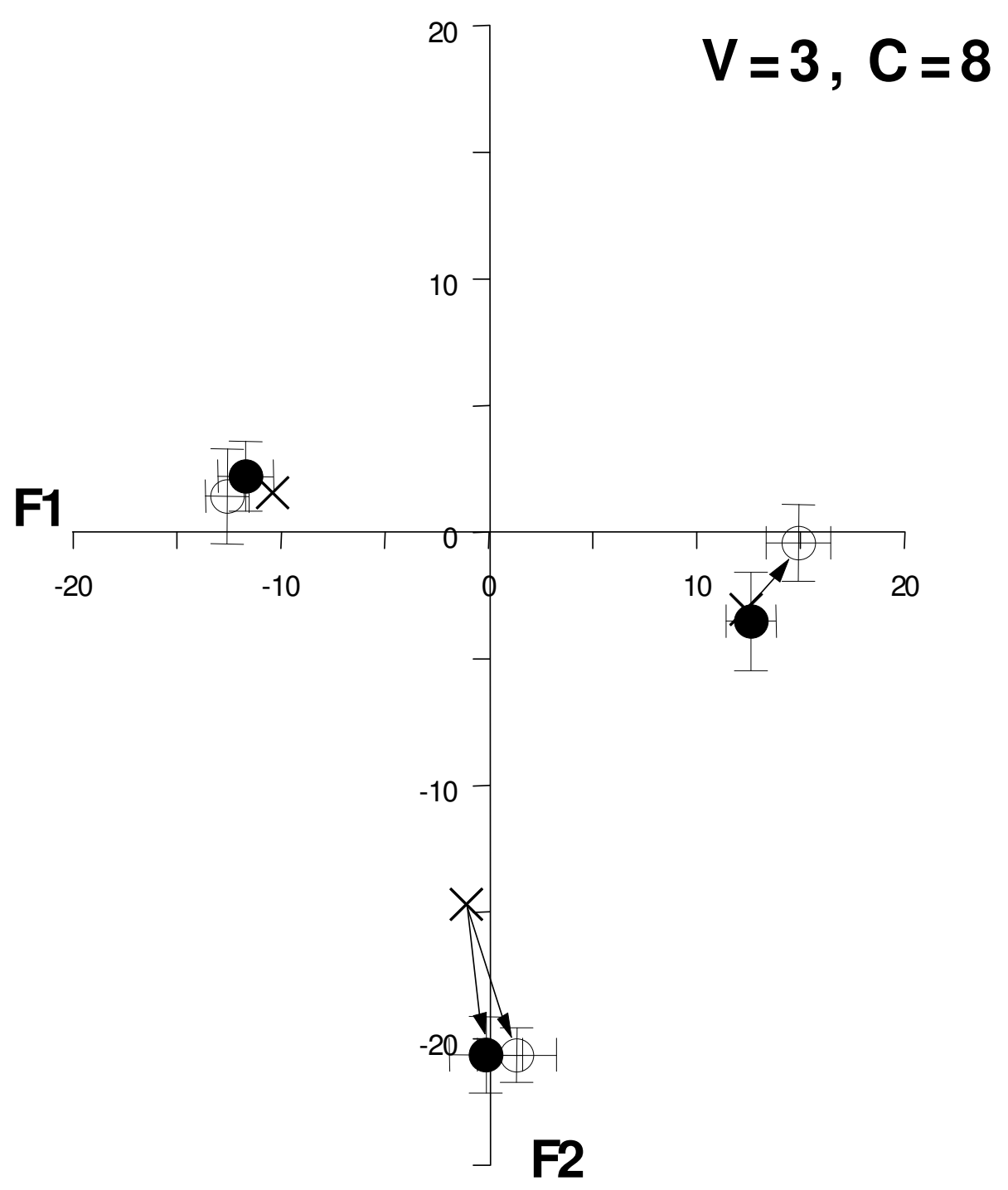


Figure 2

d)

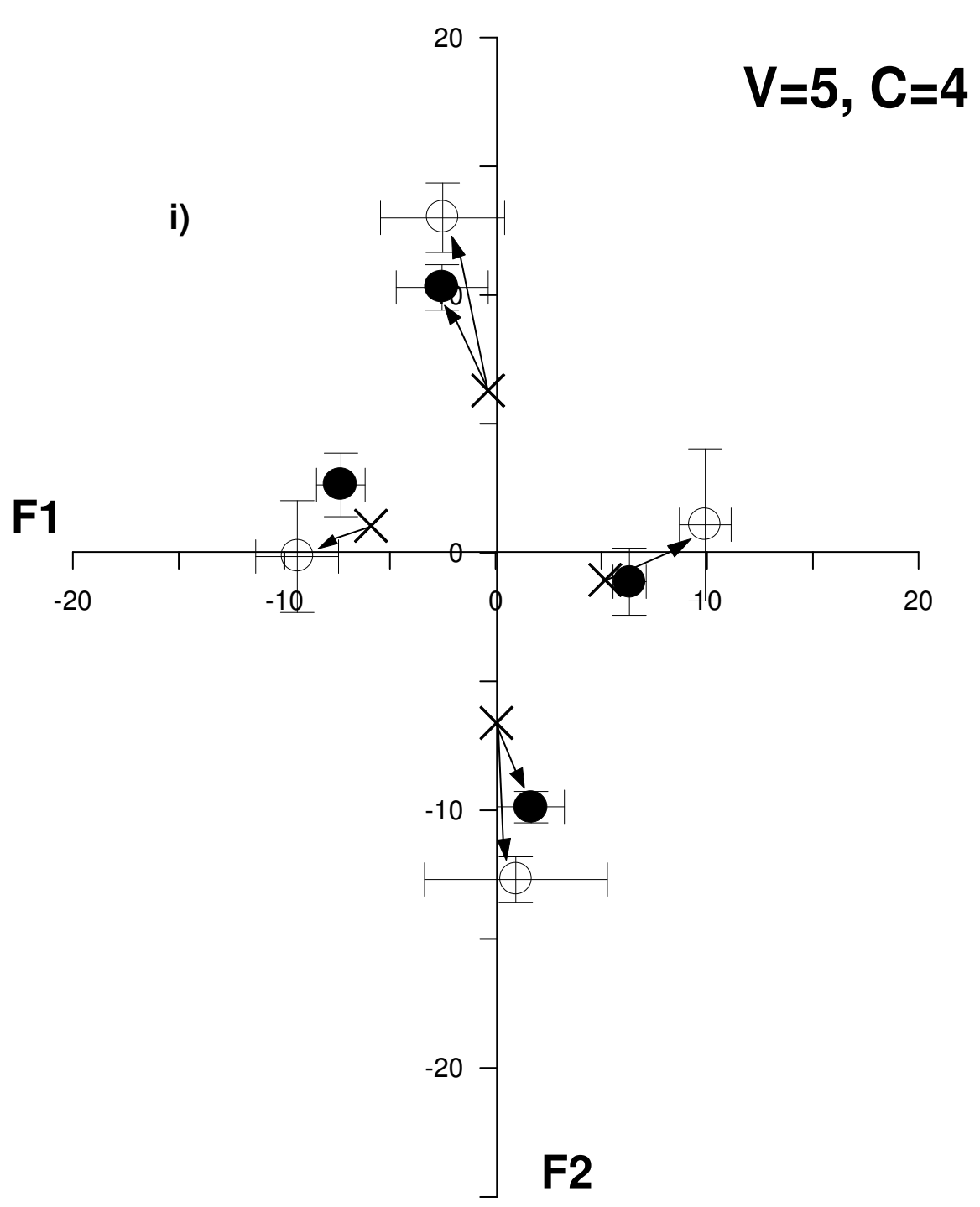


Figure 2

e)

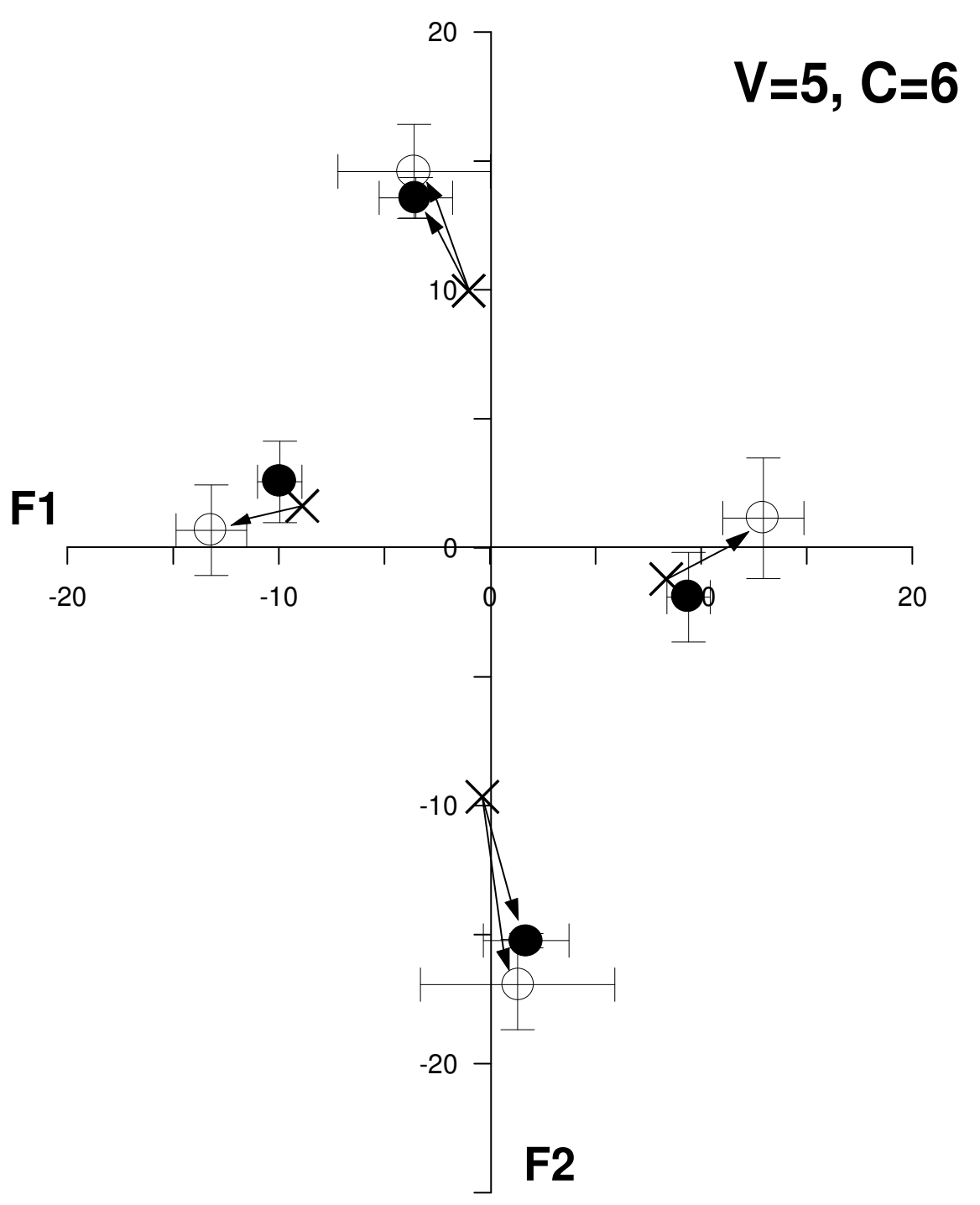


Figure 2

f)

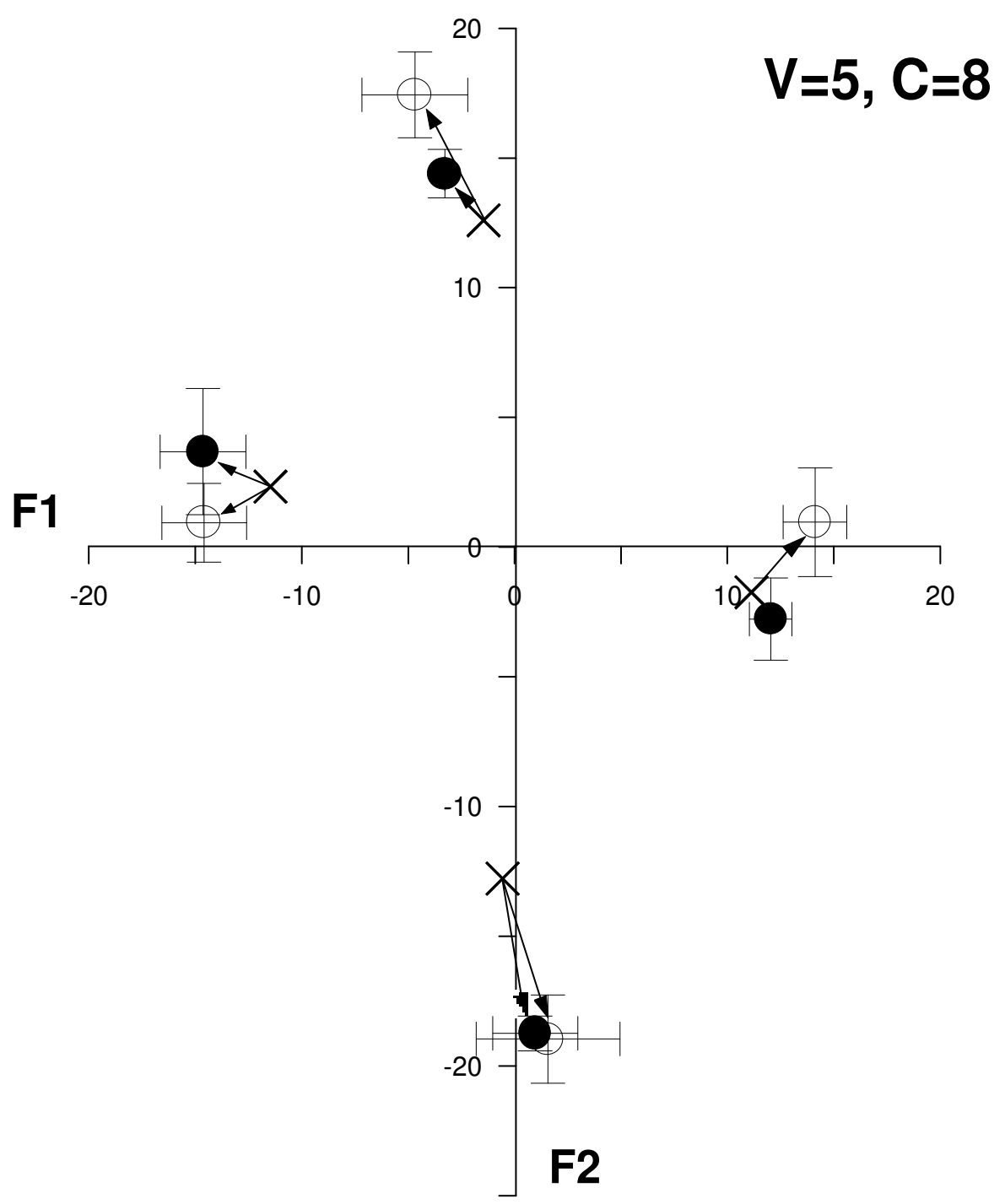


Figure 2

g)

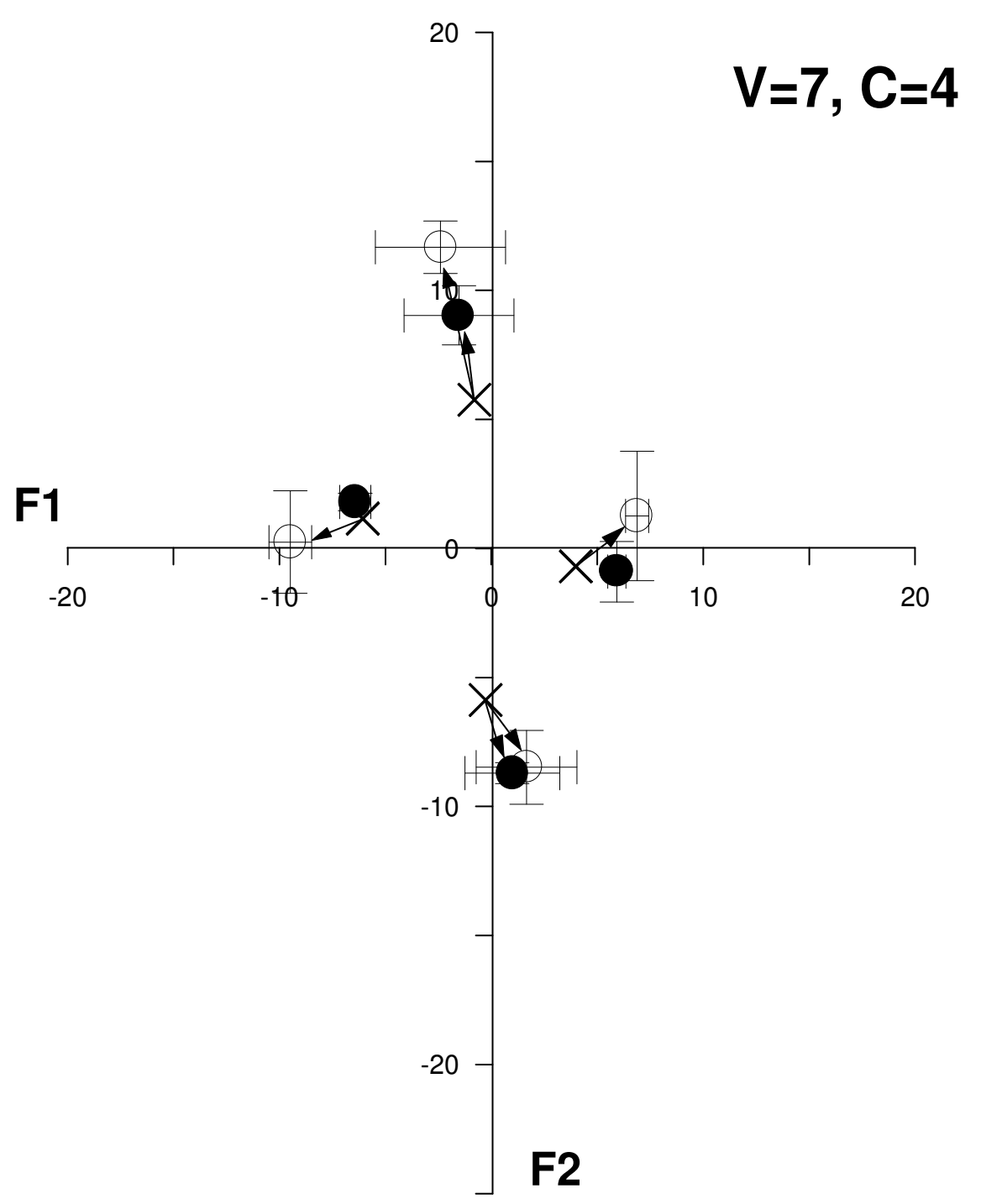


Figure 2

h)

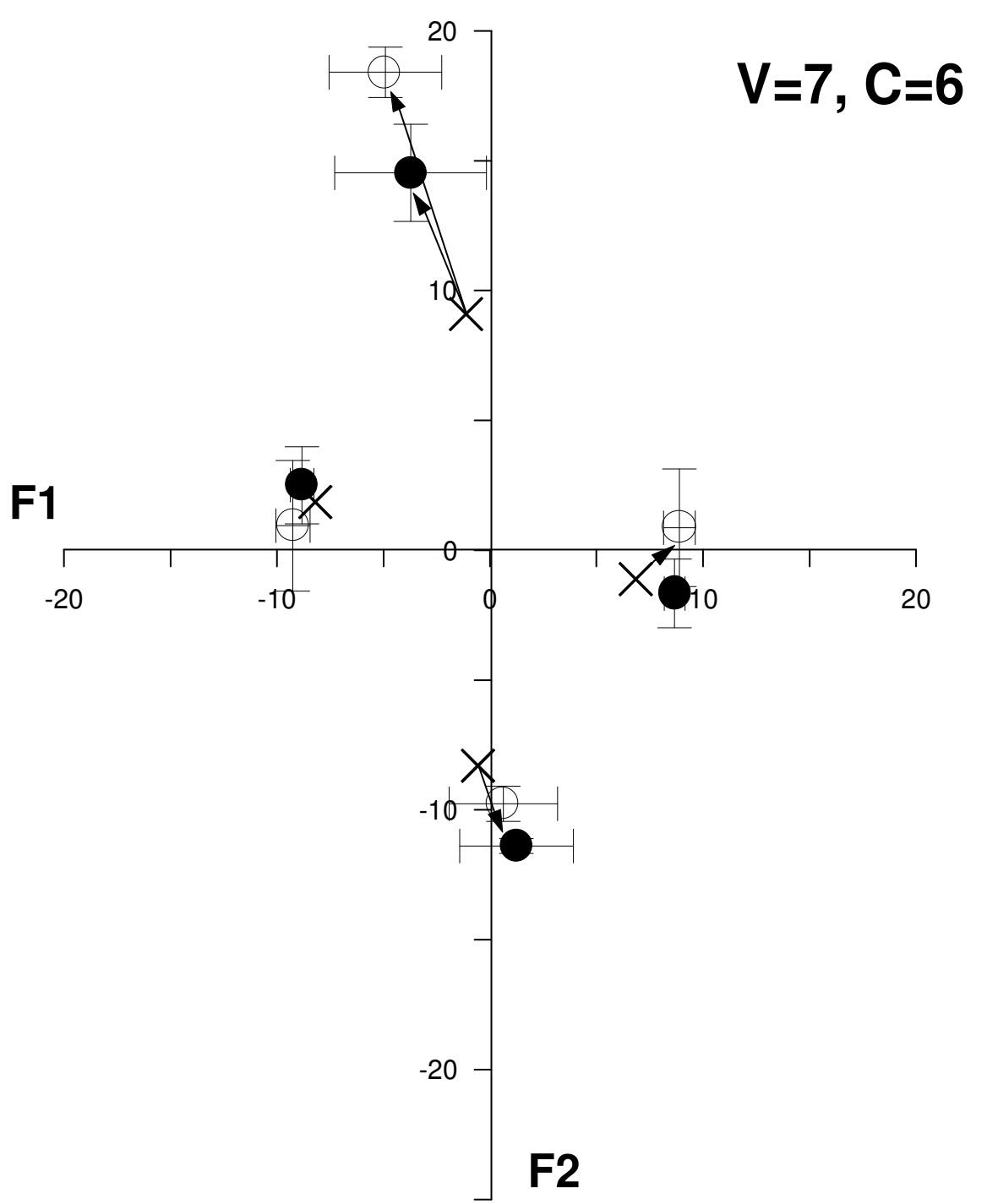


Figure 2

i)

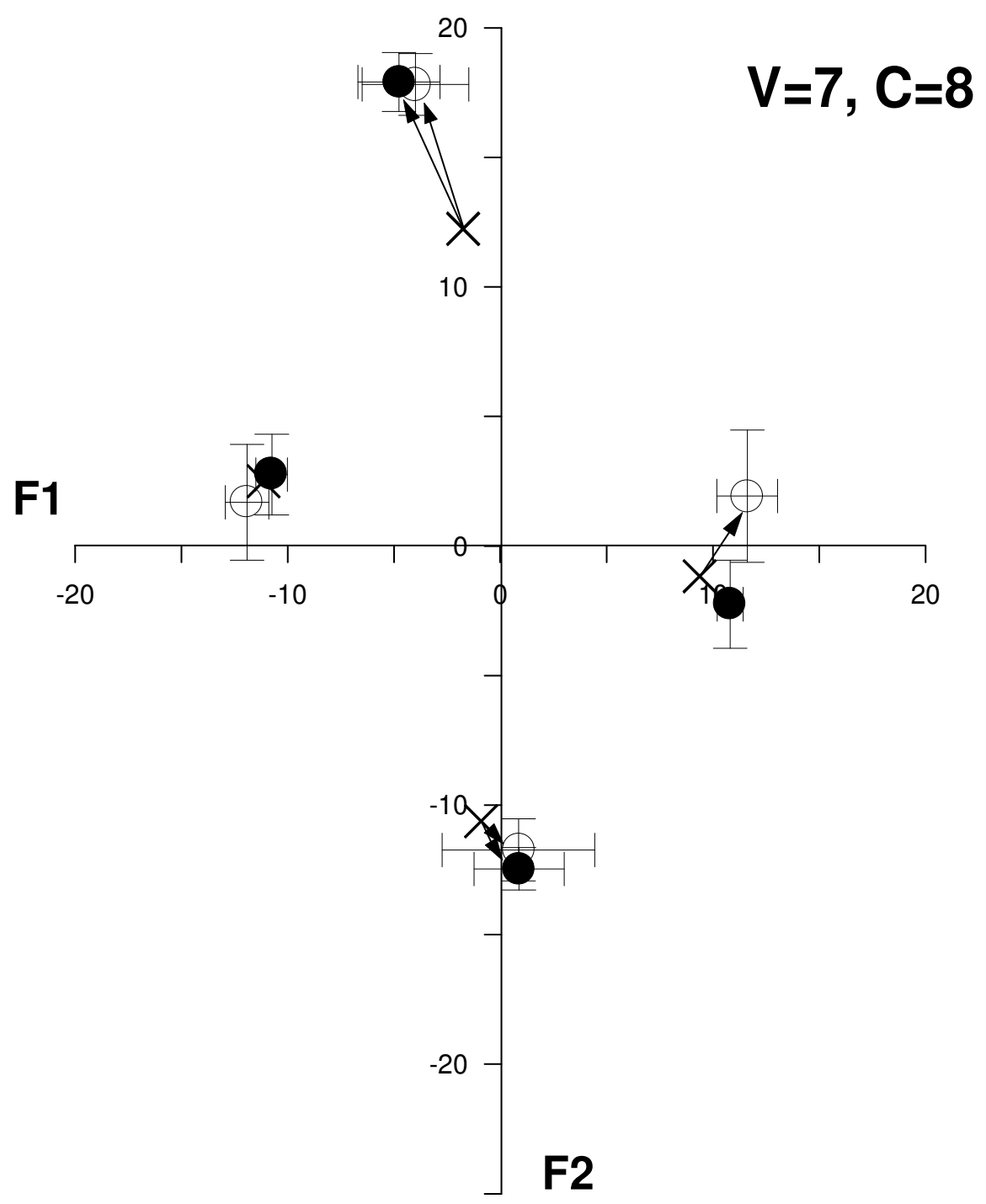


Figure 3

a)

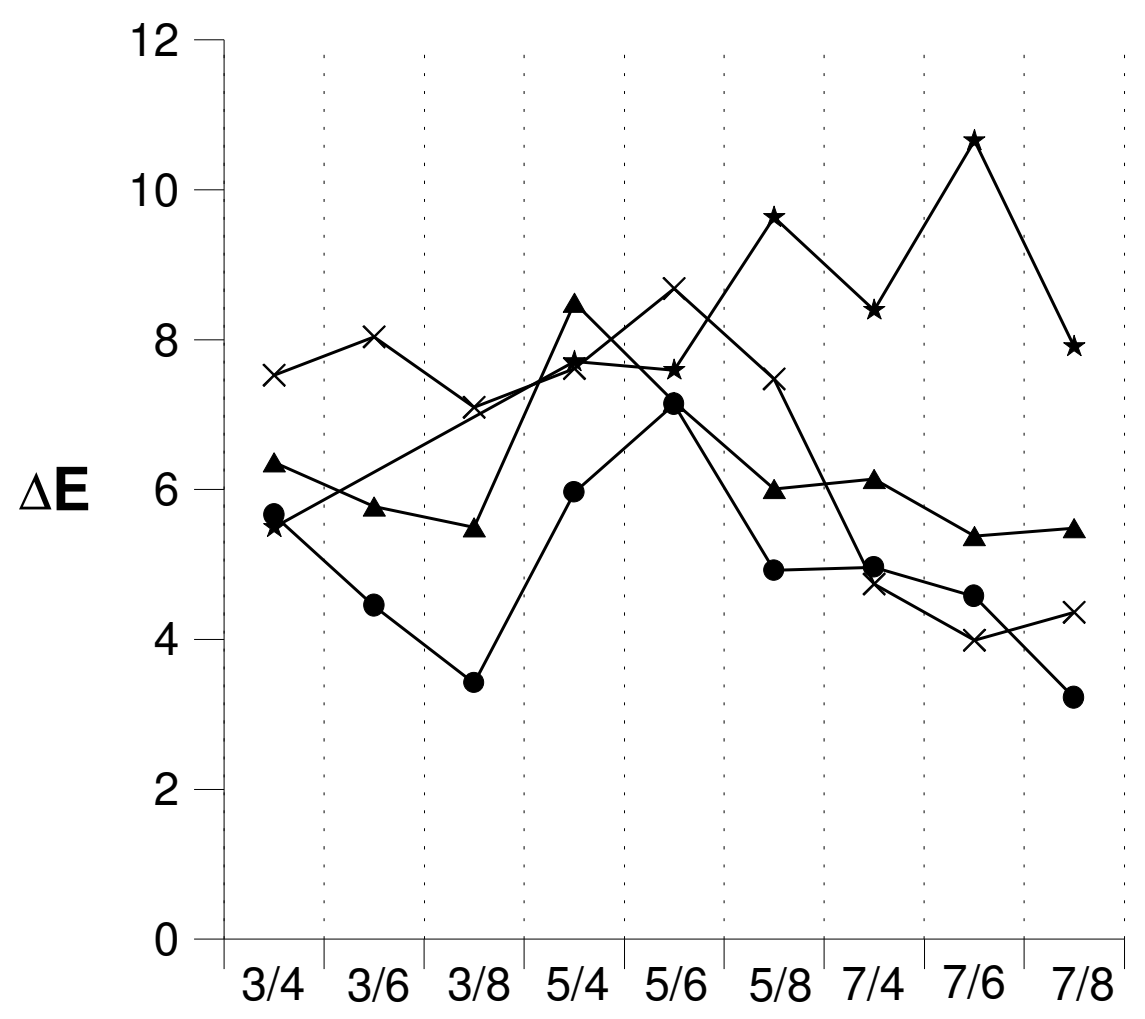


Figure 3

b)

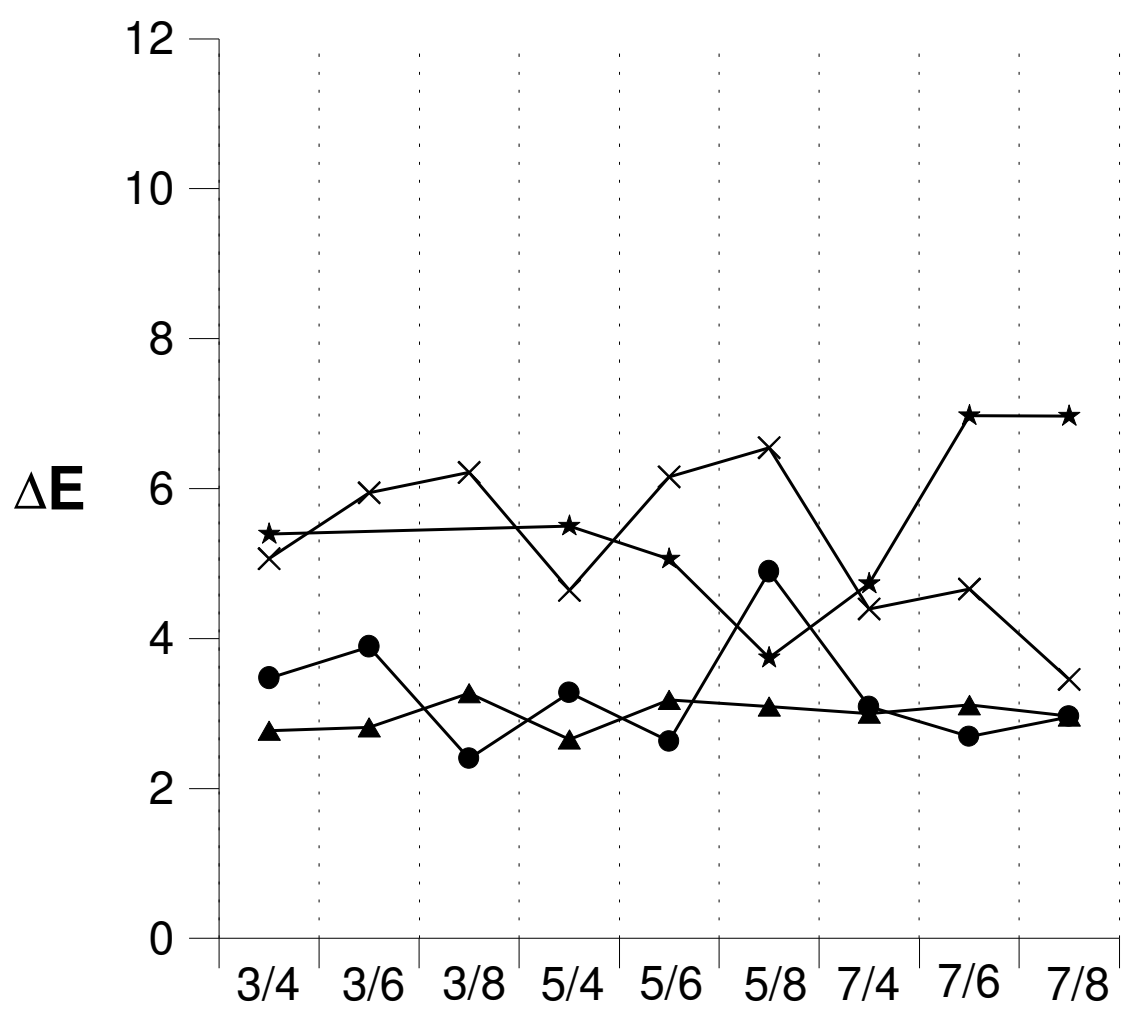


Figure 3

c)

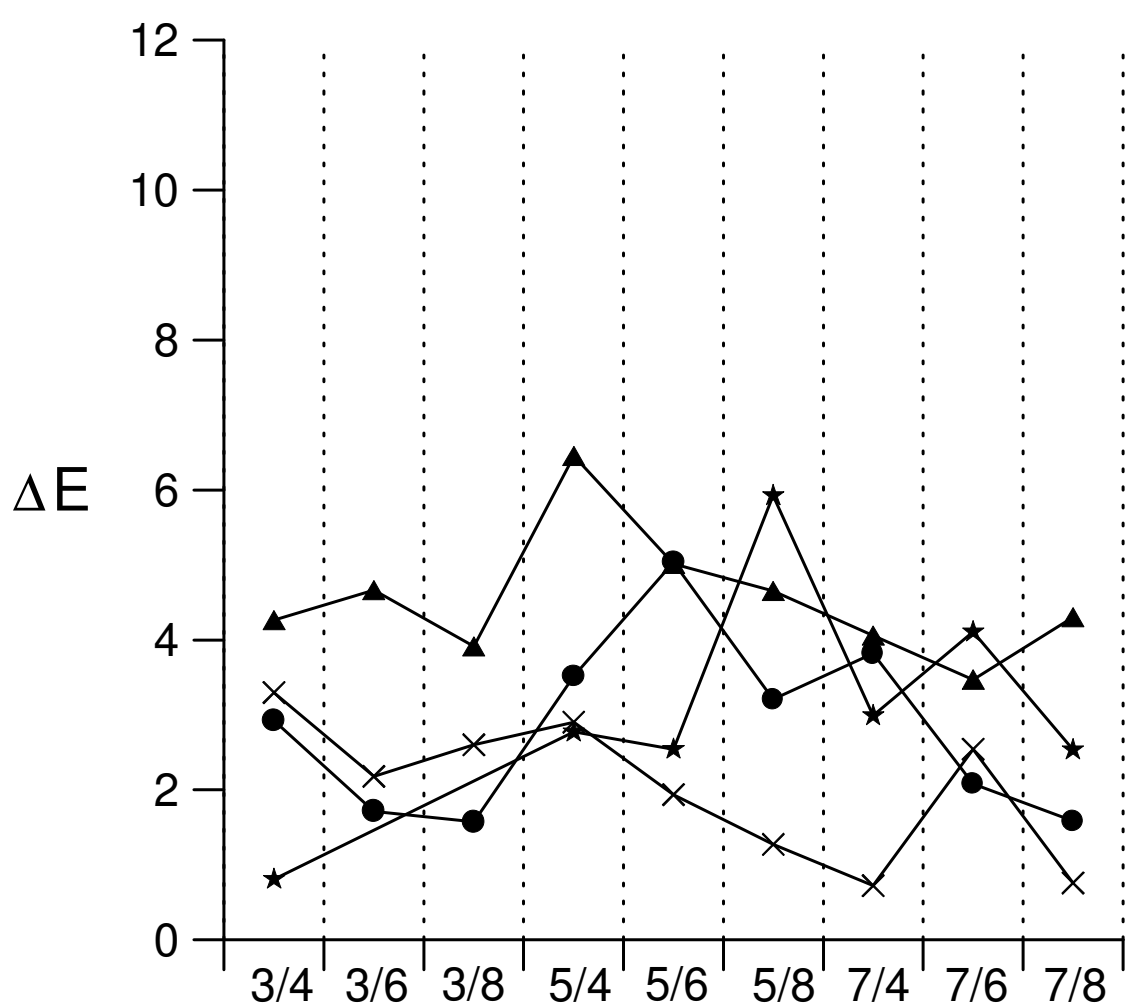


Figure 4

a)

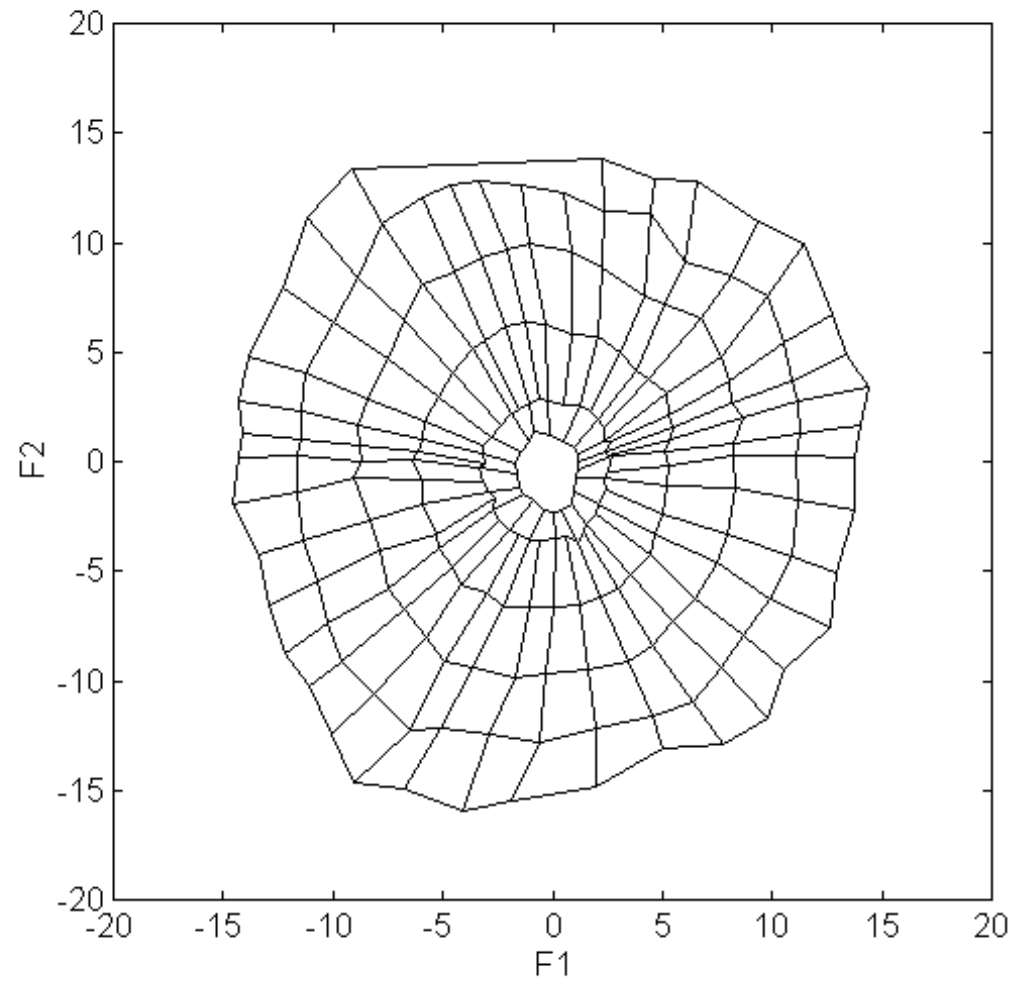


Figure 4

b)

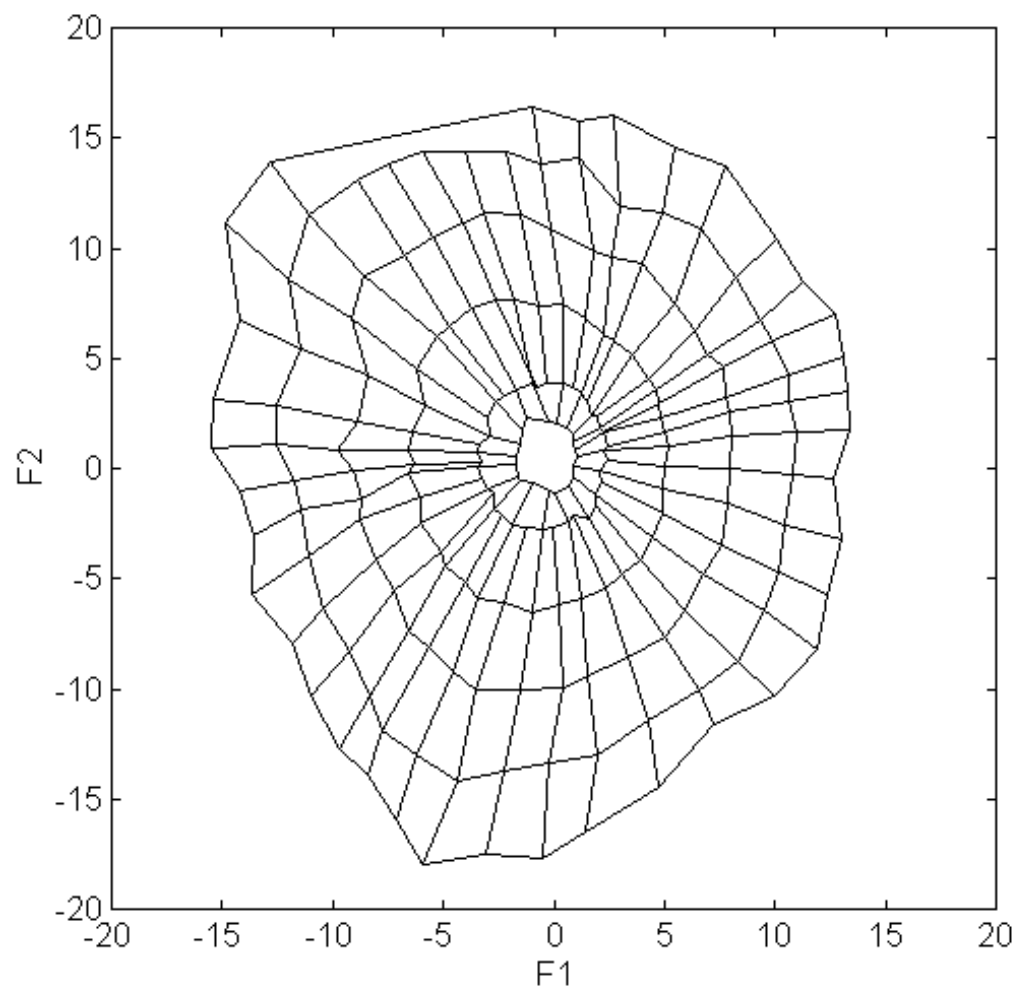




\section{Caption Tables}

Table I: SVF-total colour difference $\Delta \mathrm{E}$ between four of Breneman's corresponding pairs, obtained under illuminants $\mathrm{D}_{65}$ and $\mathrm{A}$. Original stimuli are described by their CIELUV cromaticity coordinates.

Table II: Mean $\Delta \mathrm{V}_{\mathrm{y}}, \Delta \mathrm{C}, \Delta \mathrm{h}$ and $\Delta \mathrm{E}( \pm \mathrm{sd})$ values between reference and memory matching colours.

Table III: Mean $\Delta \mathrm{V}_{\mathrm{y}}, \Delta \mathrm{C}, \Delta \mathrm{h}$ and $\Delta \mathrm{E}( \pm \mathrm{sd})$ values between reference and simultaneous matching colours.

Table IV: Mean $\Delta \mathrm{V}_{\mathrm{y}}, \Delta \mathrm{C}, \Delta \mathrm{h}$ and $\Delta \mathrm{E}( \pm \mathrm{sd})$ values between memory matching and simultaneous matching colours.

Table V: Best and worst matching colours in the memory and the simultaneous matching experiments.

Table VI: Statistical analysis. Tests for which the null hypothesis can be rejected. In these cases, the two compared samples are different. 
Table I

\begin{tabular}{|c|c|c|c|c|c|}
\cline { 2 - 5 } \multicolumn{1}{c|}{} & \multicolumn{2}{c|}{ il. A } & \multicolumn{2}{c|}{ il. D } & \multicolumn{1}{c|}{} \\
\cline { 2 - 5 } \multicolumn{1}{c|}{} & u' & v' & u' & v' & $\Delta$ E $_{\text {SVF }}$ \\
\hline Red & 0.458 & 0.522 & 0.410 & 0.508 & 0.025 \\
\hline Green & 0.193 & 0.543 & 0.137 & 0.520 & 0.023 \\
\hline Blue & 0.184 & 0.444 & 0.150 & 0.387 & 0.020 \\
\hline Yellow & 0.317 & 0.550 & 0.256 & 0.549 & 0.024 \\
\hline
\end{tabular}


Table II

\begin{tabular}{|c|c|c|c|c|c} 
& $\Delta \mathbf{V}_{\mathbf{y}}$ & $\boldsymbol{\Delta C}$ & $\Delta \mathbf{h}$ & $\Delta \mathbf{E}$ & $\mathbf{s d}(\Delta \mathrm{E})$ \\
\hline 5 PB 3/4 & -1.30 & 6.32 & 8.67 & 7.53 & 1.80 \\
\hline 5 PB 3/6 & -0.42 & 7.06 & 8.01 & 8.04 & 2.89 \\
\hline 5 PB 3/8 & 0.75 & 5.98 & 7.97 & 7.10 & 1.73 \\
\hline 5 PB 5/4 & -0.39 & 6.13 & 3.99 & 7.61 & 4.59 \\
\hline 5 PB 5/6 & -0.25 & 7.40 & 6.73 & 8.68 & 3.92 \\
\hline 5 PB 5/8 & -0.54 & 6.30 & 7.33 & 7.48 & 3.05 \\
\hline 5 PB 7/4 & 0.65 & 2.83 & 13.09 & 4.74 & 1.68 \\
\hline 5 PB 7/6 & 0.79 & 1.49 & 7.31 & 3.99 & 1.56 \\
\hline 5 PB 7/8 & -0.19 & 1.14 & 8.79 & 4.36 & 2.89
\end{tabular}

\begin{tabular}{c|c|c|c|c|c} 
& $\Delta \mathbf{V}_{\mathbf{y}}$ & $\boldsymbol{\Delta C}$ & $\boldsymbol{\Delta h}$ & $\Delta \mathbf{E}$ & $\mathbf{s d}(\boldsymbol{\Delta E})$ \\
\hline $\mathbf{5 ~ G ~ 3 / 4 ~}$ & 0.17 & 4.33 & 10.32 & 5.65 & 2.45 \\
\hline 5 G 3/6 & 0.17 & 3.31 & 5.92 & 4.45 & 2.17 \\
\hline 5 G 3/8 & 0.70 & 2.18 & 2.29 & 3.42 & 2.08 \\
\hline 5 G 5/4 & -0.26 & 3.56 & 8.92 & 5.96 & 2.49 \\
\hline 5 G 5/6 & 1.54 & 4.27 & 7.76 & 7.13 & 1.60 \\
\hline 5 G 5/8 & -0.52 & 3.02 & 8.20 & 4.92 & 1.10 \\
\hline 5 G 7/4 & 1.03 & 3.37 & 9.25 & 4.96 & 0.89 \\
\hline 5 G 7/6 & 1.38 & 0.92 & 6.55 & 4.57 & 0.80 \\
\hline 5 G 7/8 & 0.64 & 0.66 & 4.45 & 3.22 & 1.35
\end{tabular}

\begin{tabular}{l|c|c|c|c|c} 
& $\Delta \mathbf{V}_{\mathbf{y}}$ & $\boldsymbol{\Delta C}$ & $\boldsymbol{\Delta} \mathbf{h}$ & $\boldsymbol{\Delta} \mathrm{E}$ & $\mathbf{s d}(\mathbf{\Delta E})$ \\
\hline 5 RP 3/4 & -0.39 & 5.69 & 10.04 & 6.36 & 2.33 \\
\hline 5 RP 3/6 & 1.01 & 3.72 & 12.80 & 5.77 & 1.49 \\
\hline 5 RP 3/8 & 1.38 & 2.23 & 12.28 & 5.50 & 2.30 \\
\hline 5 RP 5/4 & 2.10 & 4.77 & 19.07 & 8.50 & 1.88 \\
\hline 5 RP 5/6 & 0.70 & 4.69 & 13.83 & 7.17 & 2.18 \\
\hline 5 RP 5/8 & 1.11 & 2.96 & 13.17 & 6.01 & 1.41 \\
\hline 5 RP 7/4 & 1.88 & 2.97 & 21.18 & 6.14 & 0.76 \\
\hline 5 RP 7/6 & 1.59 & 2.04 & 15.42 & 5.38 & 1.06 \\
\hline 5 RP 7/8 & 0.95 & 2.40 & 16.14 & 5.49 & 1.34
\end{tabular}

\begin{tabular}{|c|c|c|c|c|c|}
\hline & $\Delta \mathbf{V}_{\mathrm{y}}$ & $\Delta \mathrm{C}$ & $\Delta \mathrm{h}$ & $\Delta \mathrm{E}$ & $\operatorname{sd}(\Delta E)$ \\
\hline 5 Y $3 / 4$ & 1.88 & 2.99 & 9.51 & 5.49 & 2.81 \\
\hline 5 & 0.78 & 6.98 & 7.34 & 7.71 & 3.17 \\
\hline 5 Y $5 / 6$ & 1.73 & 5.05 & 7.59 & 7.59 & 4.27 \\
\hline 5 Y $5 / 8$ & 3.25 & 5.41 & 8.23 & 9.63 & 3.55 \\
\hline $5 Y 7 / 4$ & 1.26 & 6.11 & 3.49 & 8.39 & 2.15 \\
\hline & 1.29 & 9.91 & 8.04 & 10.66 & 2.79 \\
\hline 5 Y $7 / 8$ & 1.89 & 5.91 & 4.31 & 7.91 & 1.38 \\
\hline
\end{tabular}


Table III

\begin{tabular}{|c|c|c|c|c|c} 
& $\Delta \mathbf{V}_{\mathbf{y}}$ & $\boldsymbol{\Delta C}$ & $\Delta \mathbf{h}$ & $\Delta \mathbf{E}$ & $\mathbf{s d}(\Delta \mathrm{E})$ \\
\hline 5 PB 3/4 & -0.47 & 4.20 & 1.70 & 5.06 & 3.21 \\
\hline 5 PB 3/6 & -0.38 & 5.56 & 3.33 & 5.94 & 0.72 \\
\hline 5 PB 3/8 & -0.18 & 5.96 & 3.70 & 6.21 & 1.74 \\
\hline 5 PB 5/4 & -0.34 & 3.42 & 9.00 & 4.64 & 1.29 \\
\hline 5 PB 5/6 & 0.11 & 5.68 & 8.75 & 6.16 & 1.89 \\
\hline 5 PB 5/8 & -0.07 & 5.99 & 5.53 & 6.54 & 1.66 \\
\hline 5 PB 7/4 & 0.71 & 2.89 & 9.13 & 4.39 & 1.34 \\
\hline 5 PB 7/6 & -0.02 & 3.14 & 10.14 & 4.66 & 2.03 \\
\hline 5 PB 7/8 & -0.26 & 1.85 & 8.63 & 3.45 & 2.01
\end{tabular}

\begin{tabular}{l|c|c|c|c|c} 
& $\Delta \mathbf{V}_{\mathbf{y}}$ & $\Delta \mathbf{C}$ & $\Delta \mathbf{h}$ & $\Delta \mathrm{E}$ & $\mathbf{s d}(\Delta \mathrm{E})$ \\
\hline $\mathbf{5 ~ G ~ 3 / 4}$ & 0.22 & 3.05 & -7.28 & 3.47 & 1.92 \\
\hline 5 G 3/6 & 0.40 & 3.08 & -3.63 & 3.89 & 1.76 \\
\hline 5 G 3/8 & 0.19 & 1.45 & -1.79 & 2.40 & 1.37 \\
\hline 5 G 5/4 & 0.02 & 1.84 & -9.29 & 3.27 & 1.69 \\
\hline 5 G 5/6 & 0.08 & 1.28 & -3.87 & 2.63 & 1.94 \\
\hline 5 G 5/8 & 0.21 & 3.49 & -2.52 & 4.89 & 1.70 \\
\hline 5 G 7/4 & 0.84 & 0.53 & -4.75 & 3.09 & 1.47 \\
\hline 5 G 7/6 & 0.81 & 0.77 & -3.04 & 2.69 & 1.41 \\
\hline 5 G 7/8 & 0.69 & -0.30 & -1.63 & 2.96 & 1.41
\end{tabular}

\begin{tabular}{l|c|c|c|c|c} 
& $\boldsymbol{\Delta} \mathbf{V}_{\mathbf{y}}$ & $\boldsymbol{\Delta C}$ & $\mathbf{\Delta h}$ & $\boldsymbol{\Delta E}$ & $\mathbf{s d}(\boldsymbol{\Delta E})$ \\
\hline 5 RP 3/4 & -0.46 & 0.95 & 4.84 & 2.77 & 0.99 \\
\hline 5 RP 3/6 & -0.13 & 0.35 & 3.48 & 2.81 & 0.86 \\
\hline 5 RP 3/8 & 1.09 & 0.38 & -1.37 & 3.27 & 0.82 \\
\hline 5 RP 5/4 & -0.02 & 1.18 & 1.98 & 2.65 & 0.72 \\
\hline 5 RP 5/6 & -0.09 & 1.20 & -2.84 & 3.18 & 1.44 \\
\hline 5 RP 5/8 & 0.31 & 1.13 & -4.24 & 3.09 & 0.54 \\
\hline 5 RP 7/4 & 0.44 & 1.95 & 1.85 & 3.00 & 0.39 \\
\hline 5 RP 7/6 & 0.56 & 1.90 & -1.41 & 3.11 & 0.43 \\
\hline 5 RP 7/8 & 0.26 & 1.59 & -4.49 & 2.96 & 0.73
\end{tabular}

\begin{tabular}{|c|c|c|c|c|c|}
\hline & $\Delta V_{y}$ & $\Delta \mathrm{C}$ & $\Delta h$ & $\Delta \mathrm{E}$ & $\operatorname{sd}(\Delta E)$ \\
\hline $5 Y 3 / 4$ & 1.90 & 2.44 & 13.28 & 5.39 & 2.43 \\
\hline 5 Y $5 / 4$ & 0.51 & 4.31 & 10.22 & 5.50 & 1.96 \\
\hline 5 Y $5 / 6$ & 0.71 & 4.00 & 8.61 & 5.06 & 1.53 \\
\hline $5 Y 5 / 8$ & 1.13 & 2.11 & 6.15 & 3.74 & 0.27 \\
\hline & 0.78 & 3.37 & 0.79 & 4.73 & 2.02 \\
\hline $7 / 6$ & 1.01 & 5.87 & 6.55 & 6.97 & 3.56 \\
\hline $5 Y 7 / 8$ & 0.84 & 6.18 & 6.66 & 6.97 & 1.94 \\
\hline
\end{tabular}


Table IV

\begin{tabular}{l|c|c|c|c} 
& $\Delta \mathbf{V}_{\mathbf{y}}$ & $\boldsymbol{\Delta C}$ & $\boldsymbol{\Delta} \mathbf{h}$ & $\boldsymbol{\Delta} \mathbf{E}$ \\
\hline 5 PB 3/4 & -0.83 & 2.12 & 7.42 & 3.30 \\
\hline 5 PB 3/6 & -0.03 & 1.57 & 4.92 & 2.18 \\
\hline 5 PB 3/8 & 0.93 & 0.05 & 4.10 & 2.60 \\
\hline 5 PB 5/4 & -0.05 & 2.70 & -5.33 & 2.90 \\
\hline 5 PB 5/6 & -0.36 & 1.66 & -2.01 & 1.94 \\
\hline 5 PB 5/8 & -0.48 & 0.25 & 1.79 & 1.27 \\
\hline 5 PB 7/4 & -0.06 & -0.12 & 4.60 & 0.72 \\
\hline 5 PB 7/6 & 0.81 & -1.67 & -2.56 & 2.54 \\
\hline 5 PB 7/8 & 0.08 & -0.74 & 0.12 & 0.76
\end{tabular}

\begin{tabular}{|c|c|c|c|c|}
\hline & $\Delta \mathbf{V}_{\mathrm{y}}$ & $\Delta \mathrm{C}$ & $\Delta h$ & $\Delta \mathrm{E}$ \\
\hline $5 \mathrm{G} \mathrm{3} / 4$ & -0.05 & 1.21 & 16.25 & 2.93 \\
\hline $5 \mathrm{G} \mathrm{3/6}$ & -0.24 & 0.25 & 8.19 & 1.71 \\
\hline $5 \mathrm{G} \mathrm{3} / 8$ & 0.50 & 0.80 & 3.34 & 1.57 \\
\hline 5 G 5/4 & -0.27 & 1.61 & 20.67 & 3.52 \\
\hline $5 \mathrm{G} 5 / 6$ & 1.46 & 2.93 & 11.48 & 5.04 \\
\hline $5 \mathrm{G} 5 / 8$ & -0.73 & -0.48 & 10.42 & 3.21 \\
\hline $5 \mathrm{G} 7 / 4$ & -0.39 & 3.15 & 13.95 & 3.82 \\
\hline $5 \mathrm{G} 7 / 6$ & 0.57 & 0.13 & 10.01 & 2.08 \\
\hline $5 \mathrm{G} \mathrm{7/8}$ & -0.05 & 0.93 & 6.32 & 1.58 \\
\hline
\end{tabular}

\begin{tabular}{l|c|c|c|c} 
& $\boldsymbol{\Delta} \mathbf{V}_{\mathbf{y}}$ & $\boldsymbol{\Delta C}$ & $\mathbf{\Delta}$ & $\Delta \mathbf{E}$ \\
\hline 5 RP 3/4 & 0.01 & 4.23 & 2.90 & 4.26 \\
\hline 5 RP 3/6 & 1.13 & 3.41 & 8.71 & 4.66 \\
\hline 5 RP 3/8 & 0.29 & 1.81 & 14.00 & 3.91 \\
\hline 5 RP 5/4 & 2.12 & 3.54 & 16.35 & 6.45 \\
\hline 5 RP 5/6 & 0.78 & 3.40 & 16.54 & 5.02 \\
\hline 5 RP 5/8 & 0.80 & 1.79 & 16.87 & 4.65 \\
\hline 5 RP 7/4 & 1.43 & 1.00 & 19.00 & 4.06 \\
\hline 5 RP 7/6 & 1.03 & 0.11 & 16.41 & 3.47 \\
\hline 5 RP 7/8 & -0.03 & 0.60 & 21.66 & 4.30
\end{tabular}

\begin{tabular}{|c|c|c|c|c|}
\hline & $\Delta \mathbf{V}_{\mathrm{y}}$ & $\Delta \mathrm{C}$ & $\Delta \mathbf{h}$ & $\Delta \mathrm{E}$ \\
\hline $5 Y 3 / 4$ & -0.02 & 0.55 & -4.00 & 0.81 \\
\hline $5 Y 5 / 4$ & 0.27 & 2.63 & -2.91 & 2.77 \\
\hline $5 Y 5 / 6$ & 1.01 & 1.01 & -0.69 & 2.54 \\
\hline $5 Y 5 / 8$ & 2.12 & 3.29 & 2.24 & 5.92 \\
\hline $5 Y 7 / 4$ & 0.48 & 2.76 & 2.03 & 2.99 \\
\hline $5 Y 7 / 6$ & 0.28 & 4.05 & 0.60 & 4.11 \\
\hline $5 Y 7 / 8$ & 1.05 & -0.28 & -2.28 & 2.53 \\
\hline
\end{tabular}


Table V

\begin{tabular}{|c|c|c|c|c|}
\hline \multirow[b]{2}{*}{ Best matching colours } & \multicolumn{2}{|c|}{ Memory matching } & \multicolumn{2}{|c|}{$\begin{array}{l}\text { Simultaneous } \\
\text { matching }\end{array}$} \\
\hline & $\begin{array}{l}\text { G 7/8 } \\
\text { G } 3 / 8\end{array}$ & $\begin{array}{l}\Delta \mathrm{E}=3.22 \\
\Delta \mathrm{E}=3.42\end{array}$ & $\begin{array}{c}\text { G } 3 / 8 \\
\text { G 5/6 } \\
\text { RP 5/4 } \\
\text { G } 7 / 6\end{array}$ & $\begin{array}{l}\Delta \mathrm{E}=2.40 \\
\Delta \mathrm{E}=2.63 \\
\Delta \mathrm{E}=2.65 \\
\Delta \mathrm{E}=2.69\end{array}$ \\
\hline Worst matching colours & $\begin{array}{l}\text { Y 7/6 } \\
\text { Y 5/8 }\end{array}$ & $\begin{array}{c}\Delta \mathrm{E}=10.66 \\
\Delta \mathrm{E}=9.63\end{array}$ & $\begin{array}{c}\text { Y 7/6 \& 7/8 } \\
\text { PB 5/8 }\end{array}$ & $\begin{array}{l}\Delta \mathrm{E}=6.97 \\
\Delta \mathrm{E}=6.54\end{array}$ \\
\hline
\end{tabular}


Tabla VI

\begin{tabular}{c|c|c} 
PB & $3 / 6$ & $\mathrm{p}<0.0313$ \\
\hline $\mathbf{G}$ & $\mathbf{3} / 4$ & $\mathrm{p}<0.0150$ \\
\cline { 3 - 3 } & $5 / 4$ & $\mathrm{p}<0.0092$ \\
\cline { 3 - 3 } & $\mathbf{5 / 6}$ & $\mathrm{p}<0.0006$ \\
\cline { 3 - 3 } & $\mathbf{7 / 4}$ & $\mathrm{p}<0.0029$ \\
\cline { 3 - 3 } & $\mathbf{7 / 6}$ & $\mathrm{p}<0.0052$ \\
\hline $\mathbf{Y}$ & $\mathbf{3} / 4$ & $\mathrm{p}<0.0003$ \\
\cline { 3 - 3 } & $\mathbf{5 / 8}$ & $\mathrm{p}<0.0061$ \\
\cline { 3 - 3 } & $\mathbf{7 / 4}$ & $\mathrm{p}<0.0036$ \\
\hline $\mathbf{R P}$ & all & $\mathrm{p}<0.0141$
\end{tabular}

